\title{
BIANCA FRÉO
}

ESTUDO CLÍNICO DA ATIVIDADE DA CAPSAICINA EM PORTADORES DA SÍNDROME DE ARDÊNCIA BUCAL 


\section{Bianca Fréo}

Estudo clínico da atividade da capsaicina em portadores da Síndrome de Ardência Bucal

Dissertação apresentada à Faculdade de Odontologia da Universidade de São Paulo, para obter o Título de Mestre, pelo Programa de PósGraduação em Odontologia.

Área de Concentração: Diagnóstico Bucal.

Orientador: Prof. Dr. Norberto Nobuo Sugaya

São Paulo

2008 


\section{FOLHA DE APROVAÇÃO}

Fréo B. Estudo clínico da atividade da capsaicina em portadores da Síndrome de Ardência Bucal [Dissertação de Mestrado]. São Paulo: Faculdade de Odontologia da USP; 2008.

São Paulo: I_2008

\section{Banca Examinadora}

1) $\operatorname{Prof}(a) \cdot \operatorname{Dr}(a)$

Titulação:

Julgamento:

Assinatura:

2) $\operatorname{Prof}(a) . \operatorname{Dr}(a)$.

Titulação:

Julgamento:

Assinatura:

3) $\operatorname{Prof}(a) \cdot \operatorname{Dr}(a)$.

Titulação:

Julgamento:

Assinatura: 


\section{DEDICATÓRIA}

A minha amada família pela presença iluminada, por todo amor, dedicação, compreensão e incentivo imensurável que me cercam e entusiasmo demonstrado com as minhas conquistas, frutos dos valores por vocês ensinados.

Aos meus pacientes pela confiança depositada, possibilitando elucidar novos caminhos na pesquisa 


\section{AGRADECIMENTOS}

Várias pessoas contribuíram para que este trabalho chegasse a bom termo. A todos elas registro minha gratidão.

Ao meu orientador, Prof. Dr. Norberto Nobuo Sugaya por seu extremo empenho e disponibilidade irrestrita na concretização deste trabalho. Por seu apoio e equilíbrio ímpares e fundamentais, sempre presentes nos momentos mais oportunos. Meus sinceros agradecimentos por suas reflexões criativas sobre o nosso objeto de estudo.

Aos meus maravilhosos pais pela sólida formação, pela compreensão e encorajamento a prosseguir. Suas presenças foram responsáveis pela minha saúde afetiva.

Ao meu tio Márcio que me proporcionou minha formação acadêmica e possibilitou minha chegada ao Mestrado, meus eternos agradecimentos.

A minha amiga e sócia querida Desiree Cavalcanti por sua dedicação única, sem a qual meu caminho na realização desse projeto se tornaria impossível, deixo aqui meu afetivo muito obrigada.

Aos meus amigos minhas melhores referências nos momentos decisivos.

Ao Prof. Dr. Gilberto Marcucci e ao Prof. Dr. Dante Antônio Migliari, (Titular da Disciplina de Estomatologia Clínica), pela oportunidade de ingresso no curso de PósGraduação.

Aos professores da Disciplina de Estomatologia Clínica, por todo acolhimento e ensinamento gentilmente dispensados. 
A todos os funcionários, colegas e amigos, pelo constante companheirismo e auxílio. Com todos vocês este trabalho tornou-se menos pesado.

A Prof. Sibele Sarti Penha pela realização da análise estatística.

Ao CAPES - Coordenação de Aperfeiçoamento de Pessoal de Nível Superior, que me concedeu uma bolsa de auxílio à pesquisa durante a realização do Mestrado, fato este que muito contribuiu para a viabilização desta dissertação. 
Que os vossos esforços desafiem as impossibilidades, lembrai-vos de que as grandes coisas do homem foram conquistadas do que parecia impossível.

Charles Chaplin

O importante é estar pronto para, a qualquer momento, sacrificar o que somos pelo que podemos vir a ser.

Charles Du Bois

Sua tarefa é descobrir o seu trabalho e, então, com todo o coração, dedicar-se a ele.

Buda

Nunca encontraremos a verdade se nos conformarmos com o que foi encontrado. Gilbert de Tournai 
Fréo B. Estudo clínico da atividade da capsaicina em portadores da Síndrome de Ardência Bucal [Dissertação de Mestrado]. São Paulo: Faculdade de Odontologia da USP; 2008.

\section{RESUMO}

A Síndrome de Ardência Bucal (SAB) caracteriza - se por sensação de ardor, com ausência de sinais clínicos ou laboratoriais associados. A etiopatogenia é desconhecida, inexistindo protocolo terapêutico satisfatório. O objetivo deste trabalho foi avaliar a eficácia da aplicação tópica de capsaicina, como alternativa terapêutica, em um grupo de pacientes portadores da SAB, além de investigar, nessa população, indicativos de ansiedade e depressão, correlacionando estes últimos aspectos com a resposta à terapêutica aplicada. Constituiu-se um grupo de vinte indivíduos portadores da síndrome, todos de acordo com os termos do consentimento esclarecido. Quinze sujeitos constituíram o grupo teste (GT) e foram tratados com capsaicina, em aplicações diárias, durante três semanas, repetindo-se o ciclo por quatro semanas após uma semana de intervalo. O grupo controle (GC) foi tratado com o creme base utilizado como veículo da capsaicina, durante o mesmo período. Ambos foram controlados após 30 dias do término da medicação. A evolução dos sintomas foi controlada por escala visual de sintomatologia (EVS) e questionário acerca do efeito global percebido (EGP). A intensidade média do sintoma de ardência antes do início dos ciclos de tratamento, mensurado pela EVS, foi de 5,1 (GT) e 4,4 (GC). Ao final da quarta semana o GT mostrou redução dos sintomas (EVS=3,6), enquanto o GC declarou aumento da sintomatologia 
$(E V S=4,8)$. No $G T$, entre a quarta e a oitava semana houve redução dos sintomas da ordem de 8,3\%, e entre a oitava e a décima segunda semana observou-se aumento de $13,5 \%$ da sintomatologia. No GC houve $22.8 \%$ de piora (EVS=5,75) entre o início e a décima segunda semana. Ao EGP houve pelo menos algum alívio do sintoma em seis pacientes (40\%) do GT e em um paciente do GC (20\%). Quatro pacientes $(26,6 \%)$ reportaram remissão total do sintoma após tratamento com capsaicina e um paciente (20\%) do controle. Para três pacientes do GT e dois do GC não houve modificações do sintoma. Houve relato de piora em dois pacientes $(13,3 \%)$ do GT e um (20\%) do GC. Oito pacientes do GT apresentaram alto nível de ansiedade e sete níveis médios. No GC um paciente apresentou nível baixo, três mostraram valores médios e um classificou-se como alto. Ao CES-D valores indicativos de depressão foram registrados por dez pacientes $(66,6 \%)$ do GT e $40 \%$ (02) do GC. Concluímos que a capsaicina apresentou efetividade no controle da sintomatologia da SAB, parecendo haver correlação com a intensidade inicial de sintomas e manutenção do uso do medicamento. Além disso, houve correlação entre alto nível de ansiedade e indicativos de depressão, embora não se tenha percebido influência destes aspectos sobre a resposta terapêutica.

Palavras-Chave: síndrome de ardência bucal; ardor; medicamentos; capsaicina; dores neuropáticas 
Fréo B. Clinical study activity of capsaicin in patients with Burning Mouth Syndrome [Dissertação de Mestrado]. São Paulo: Faculdade de Odontologia da USP; 2008.

\section{ABSTRACT}

Burning mouth syndrome (BMS) is characterized by an oral burning sensation, with no corresponding clinical signs or laboratory abnormalities. The etiology is unknown, and there was no satisfactory treatment available. The objective of this study was to evaluate the effectiveness of topical use of capsaicin, as an alternative therapy in a group of BMS patients, as well as to correlate anxiety and depression levels to response to the therapy applied. Twenty BMS individuals in accordance to the terms to informed consent comprised the study group. Fifteen subjects were allocated to the test group (TG) and were treated with capsaicin, in daily applications for three weeks, one-week interval and an additional treatment cycle of four weeks. The control group (CG) was treated with the cream base used as a vehicle of capsaicin preparation, during the same period. All patients were examined 30 days after discontinuation of the medication. Results were assessed through a visual analogue scale (VAS) and a questionnaire on the global perceived effect (GPE). The average symptoms intensity before treatment, on EVS, was 5.1 (TG) and 4.4 (CG). At the fourth week control, TG presented reduction on the level of symptoms (EVS = 3.6), while CG presented an increase of symptoms intensity (VAS $=4.8$ ). In the TG, between fourth and eighth week of follow-up, symptoms decreased around 8.3\%, 
and between the eighth and twelfth week there was an increase of $13.5 \%$ on symptoms intensity. In the CG it was registered $22.8 \%$ of worsening (EVS $=5.75$ ) between the beginning of the study and the twelfth week of control. On GPE assessment, six patients (40\%) of TG and one patient of CG (20\%), presented some relief of symptoms; four patients TG (26.6\%) reported total remission of symptoms after treatment with capsaicin and one patient (20\%) of control; three patients of TG and two of the CG remained unaltered. There were reports of worsening in two patients (13.3\%) of TG and one (20\%) of the CG. Eight patients of TG showed a high level of anxiety and seven moderate levels. In CG one patient presented low level, three showed a moderate level and one was ranked as having a high level of anxiety. CES-D suggested traits of depression in ten patients (66.6\%) of TG and $40 \%$ (2) of the CG. We concluded that capsaicin is effective in controlling the burning symptom of BMS, suggesting some correlation with initial symptoms intensity and the maintenance of drug use. Moreover, there was some correspondence between high levels of anxiety and traits of depression, but it was not perceived influence of these aspects to the therapeutic response.

Keywords: Burning mouth syndrome; burning; drugs; capsaicin; neuropathic pain 


\section{SUMÁRIO}

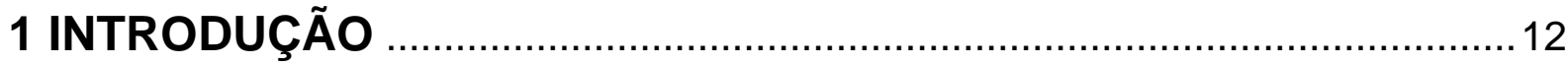

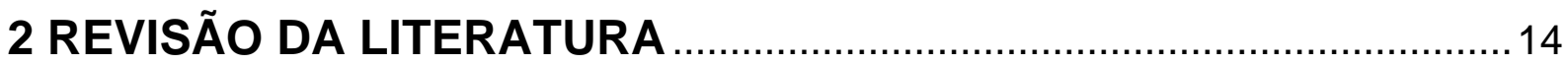

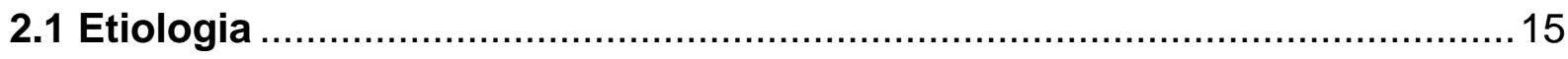

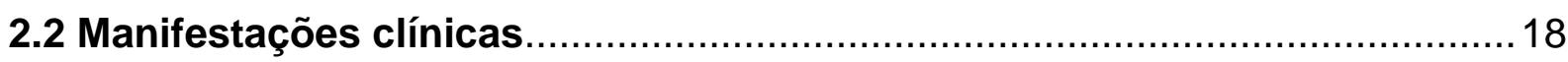

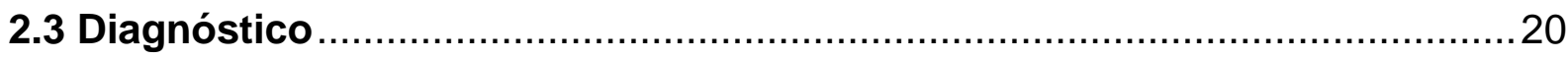

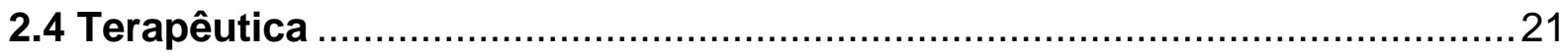

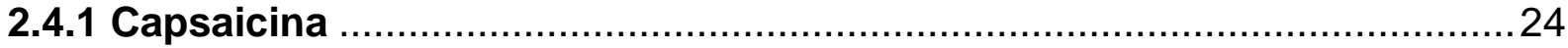

2.5 Fatores psicológicos associados .............................................. 30

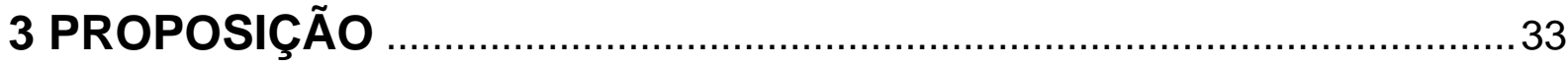

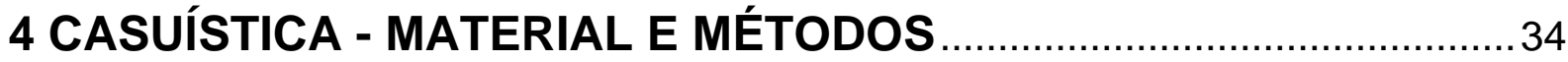

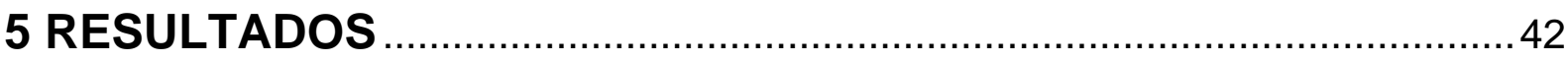

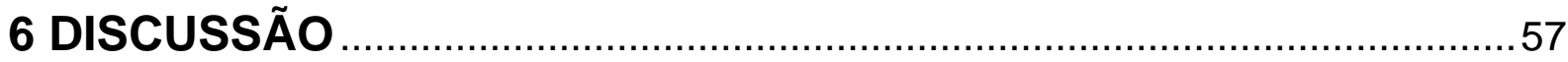

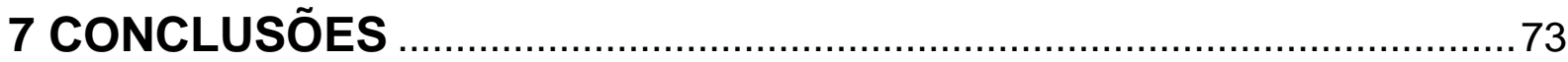

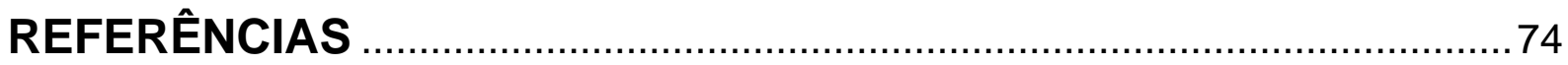

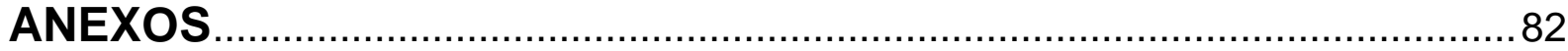




\section{INTRODUÇÃO}

A SAB tem sido crescentemente estudada, em virtude de sua relativa freqüência, da falta de esclarecimento de sua etiologia e, principalmente, devido à ausência de uma alternativa terapêutica satisfatória.

O fato do sintoma não se acompanhar de alterações objetivas em mucosa suscitou, durante muito tempo, a suspeita de que se tratasse de uma alteração psicogênica que deveria conduzir o paciente portador à Psiquiatria ou a um psicoterapeuta. Atualmente a condição vem sendo mundialmente estudada, conseqüente à sua distribuição universal e ao próprio esclarecimento da população, entretanto esse investimento ainda não resultou em resultados práticos significativos.

A tendência atual é a de se considera-la como distúrbio neuropático levandose em conta uma série de indícios que pacientes portadores freqüentemente apresentam, quais sejam alterações do paladar, resposta antagônica à aplicação de anestésicos tópicos, resposta irregular a testes de reflexos nervosos como o "piscar dos olhos" e a própria sensação de ardência diuturna que pouco se modifica em sua evolução. Assumindo-se esta linha hipotética de etiopatogenia, as possibilidades terapêuticas são ainda limitadas.

Indubitavelmente parece existir a concorrência importante de fatores emocionais nesses pacientes, desde que terapêuticas placebo produzem benefício a parte dos doentes, entretanto, a utilização de ansiolíticos e anti-depressivos vem sendo proposta há algum tempo e não tem se mostrado satisfatória. 
A Clínica de Diagnóstico Bucal da FOUSP já recebeu ao longo dos últimos anos um número significativo de pacientes portadores da SAB e tem procurado desenvolver protocolos terapêuticos para essa população. Técnicas de acupuntura, laser de baixa potência e ácido alfa-lipóico constituem alguns dos protocolos que foram investigados ou vem sendo desenvolvidos. A capsaicina comparece à literatura como uma das possibilidades de controle da sintomatologia associada à $S A B$, desde que sua ação sobre as fibras sensoriais do tipo $C$ interfere na condução do estímulo nervoso e, por esse motivo candidatou-se a uma investigação clínica em nosso Departamento.

Os portadores da SAB constituem-se, em geral, em pacientes de difícil manejo. A maior parte deles sofre com a condição há vários anos e já percorreu diversos profissionais. Já foram tratados com ceticismo e já experimentaram terapêuticas que nenhum benefício produziu. De outro lado, os profissionais, especialmente os cirurgiões-dentistas, não dispõem de protocolos terapêuticos estabelecidos e não são capazes de avaliar adequadamente a interferência emocional sobre o quadro que o paciente apresenta.

O desafio está à mesa e nos serviu de incentivo para seguir investigando alternativas mais adequadas ao manejo dos pacientes portadores dessa síndrome, cujo diagnóstico é estabelecido por exclusão e cuja avaliação terapêutica depende unicamente da informação subjetiva dos pacientes, o que, sem dúvida, frustra enormemente grande parte dos profissionais. 


\section{REVISÃO DA LITERATURA}

A SAB, outrora também conhecida (hoje ainda em pequenos círculos) como glossodinia, glossopirose, estomatodinia e, entre outros termos, disestesia bucal, é caracterizada pela sensação de ardor em mucosa clinicamente normal, ou seja, a queixa do paciente não corresponde a sinais clínicos evidentes (BERGDHAL; BERGDHAL, 1999; GRUSHKA; CHING; EPSTEIN, 2006; GRUSHKA; EPSTEIN; GORSKY, 2002a; SANTORO; CAPUTO; PELUSO, 2005; GRUSHKA; CHING; EPSTEIN, 2006).

Considerada condição crônica e atípica, afeta mais freqüentemente mulheres no climatério, numa proporção de cerca de nove mulheres para cada homem (GRUSHKA; EPSTEIN; GORSKY, 2002a ; HAKEBERG et al., 1997; LAMEY, 1996; VAN DER PLÖEG et al., 1987; VAN DER WÄAL, 1990). A incidência da SAB na população em geral não é bem conhecida, estima-se, no entanto, que cerca de 0,4\% da população dos Estados Unidos seja afetada por esta doença (MUZIKA; DE ROSSI, 1999).

Estudo realizado com 1427 indivíduos na Suécia; 669 homens e 758 mulheres, média de idade de 59 anos; apontou prevalência de SAB de 3,7\% (BERGDHAL; BERGDHAL, 1999). Pajukosky et al. (2001), em estudo realizado na Finlândia, com indivíduos mais idosos, observou uma prevalência ainda maior: 12,6\% de 75 pacientes hospitalizados (média de idade 82 anos) e 18,3\% de 266 idosos não institucionalizados (média de idade 77 anos). 


\subsection{Etiologia}

A etiologia da SAB ainda é incerta. A maioria dos estudos mais recentes considera origem multifatorial para a doença (BERGDHAL; BERGDHAL, 1999; GRUSHKA, 1987; GRUSHKA; CHING; EPSTEIN, 2006; GRUSHKA; EPSTEIN; GORSKY, 2002a; LAMEY, 1996; SHIP et al., 1995; VAN DER PLÖEG et al., 1987; VAN DER WÄLL, 1990).

Os fatores supostamente relacionados estão divididos em quatro grupos. $\mathrm{O}$ primeiro inclui fatores locais: infecções (candida, bactérias inespecíficas, fusoespiroqueta), xerostomia, alteração do paladar, hipogeusia (diminuição do paladar) ou disgeusia, na qual o paciente refere gosto persistente principalmente metálico, salgado e amargo, alergênicos (corantes, conservantes) e dentários (próteses, traumas). O segundo inclui fatores de origem sistêmica como: nutricionais (ferro, complexo B, ácido fólico e zinco), hormonais (diabetes mellitus, hipotiroidismo e menopausa), medicamentosas (antibióticos, antidepressivos tricíclicos, antiretrovirais) e alterações das glândulas salivares (Sjögren, fibromialgia, irradiação). O terceiro envolve condições psicogênicas como cancerofobia, depressão, ansiedade e transtorno obsessivo compulsivo, (BERGDHAL; BERGDHAL, 1999; LAMEY, 1996; SHIP et al., 1995; VAN DER PLÖEG et al., 1987; VAN DER WÄLL, 1990). Um quarto fator seria de causa idiopática (CERCHIARI et al., 2006).

Investiga-se a participação de outros fatores na etiopatogenia da $\mathrm{SAB}$, como alterações neurológicas e no mecanismo de transmissão da dor (FORMAKER; MOTT; FRANK, 1998; FORMAKER; FRANK, 2000; TANAKA et al., 2002). 
Aparentemente há interações centrais e periféricas, entre os sistemas nociceptivo da dor e gustatório, na etiopatogenia da SAB. Formaker, Mott e Frank (1998) num estudo que envolveu 33 pacientes com SAB, observaram que a disgeusia diminuía em intensidade após a aplicação de anestésico tópico, sugerindo que a disgeusia nestes pacientes está relacionada à ativação de mecanismos gustatórios periféricos. Ainda neste relato, foi reportado que a anestesia tópica bloqueava os sintomas de ardor em um terço dos pacientes, enquanto em outros havia um aumento da sensação de ardor após o mesmo procedimento, o que levou à suposição de uma origem central para o ardor em alguns sujeitos da pesquisa.

Sugere-se que ocorra uma interação entre os mecanismos de nocicepção e gustação no sistema nervoso central, e possível dano resultante em ardência bucal (BRAILO et al., 2006; FEMIANO, 2004).

Pesquisas têm relacionado a ocorrência de $S A B$ principalmente à disfunção sensorial e às alterações neuropáticas (FORSSELL et al., 2002; HAGELBERG et al., 2003; JÄÄSKELÄINEN; FORSSEL; TENOVUO, 1997; PATTON et al., 2007). A doença é classificada por alguns autores, entre as neuropatias de pequenas fibras, ao lado de outras doenças como a neuropatia diabética (GAO; WANG; WANG, 2000; LAURIA et al., 2005; JÄÄSKELÄINEN; FORSSEL; TENOVUO, 1997; YILMAZ et al., 2007).

Lauria et al. (2005) através da realização de biópsia nos terços anteriores da língua de pacientes com SAB e controles, verificaram uma redução substancial na densidade de fibras epiteliais neurais nas amostras $S A B$, com uma tendência de correlação com o tempo de evolução dos sintomas. Além disso, as fibras neurais epiteliais e subpapilares mostraram alterações morfológicas difusas, refletindo 
degeneração axonal, o que sugeriu associação da $S A B$ com neuropatia trigeminal de pequenas fibras.

Grushka, Sessle e Howley (1987) testaram modalidades sensoriais (tato, dor e função sensorial térmica) entre setenta e dois indivíduos com SAB e quarenta e três controles. A tolerância à dor foi significativamente menor, no ápice lingual, para os pacientes em relação aos controles, sugerindo alterações específicas em funções sensoriais centrais e periféricas.

Ito et al. (2002) avaliaram o limiar da dor através da estimulação térmica em língua de vinte pacientes diagnosticados com ardência bucal, observando limiar menor do que no grupo controle. A duração e complexidade da queixa de ardor foram consideravelmente maiores após a remoção do estímulo em relação aos controles, mostrando possível relação entre a dor e disfunção periférica na língua e / ou disfunção central.

Eliav et al. (2007) em estudo envolvendo vinte e dois pacientes observaram evidências de hipofunção do nervo corda do tímpano em 82\% dessa casuística (59\% unilateral e $23 \%$ bilateral). A hipofunção unilateral pode ser suficiente para produzir sensação generalizada de ardor para além da área de inervação.

Em seus estudos, Jääskeläinen, Forssel e Tenovuo (1997) pesquisaram o possível mecanismo neuropático relacionado à doença por uma avaliação eletrofisiológica do sistema trigêmeo-facial usando o reflexo de piscar. Com estimulação não noxial do nervo supraorbital, os pacientes de SAB mostraram, com maior freqüência, anormalidades relacionadas à dor e ao reflexo de piscar quando comparados aos controles. Esses desvios do reflexo de piscar parecem estar relacionados à longa duração da doença, que normalmente ocorre, sugerindo um possível envolvimento patológico do sistema nervoso. A avaliação do reflexo de 
piscar demonstrou que um quinto destes pacientes apresenta neuropatia trigeminal ou patologia de tronco cerebral e outro quinto deles mostraram aumento de excitabilidade do reflexo de piscar. Em aproximadamente três quartos dos pacientes um ou mais limiares sensoriais estavam anormais, indicando disfunção de pequenas fibras, a maioria com hipoestesia. Os achados evidenciam envolvimento de componente neuropático na patologia em questão.

Para Puri et al. (2005) a função neuroprotetora do estrógeno sobre o sistema dopaminérgico nigroestriatal e o seu declínio com a menopausa, poderia explicar a predileção da doença pelo sexo feminino e faixa etária. Estudos em modelo animal suportam o efeito protetor do estrógeno sobre o sistema dopaminérgico central por demonstração de modulação direta do gânglio trigeminal pelo estrógeno.

\subsection{Manifestações clínicas}

O sintoma referido é geralmente dor do tipo queimação, de intensidade entre moderada e severa, sendo a língua o local mais acometido, ao menos $60 \%$ dos casos, seguida do lábio inferior (AMENÁBAR et al., 2008). A ardência é quase sempre bilateral e simétrica. Mucosa jugal, assoalho bucal e orofaringe constituem localizações menos freqüentes (BERGDHAL; BERGDHAL, 1999; GORSKY; SILVERMAN; CHINN, 1991; LAMEY, 1996; VAN DER WÄAL, 1990).

Algumas vezes, em um mesmo paciente, pode-se observar o sintoma de ardor em boca e em outras regiões do corpo, sendo mais freqüente a região anogenital, quando tal sucede (GAITONDE et al., 2002; LAMEY, 1996). 
Lamey (1998) na tentativa de agrupar os pacientes de acordo com as características de suas queixas, classificou a SAB em três subtipos:

SAB tipo 1- Sintomas de ardor diário. A ardência, no entanto, não está presente ao levantar-se, mas surge com o decorrer do dia, piorando ao anoitecer. Ocorre em aproximadamente 35\% dos pacientes. Pacientes de SAB tipo 1 são mais difíceis de tratar porque uma grande proporção deles apresenta ansiedade crônica, que representa o mais difícil obstáculo para o tratamento (LAMEY, 1996).

SAB tipo 2 - Neste caso, os pacientes têm ardência todos os dias e ela está presente ao levantar-se, sem modificações durante o dia ou noite; observa-se esta queixa em cerca de $55 \%$ dos pacientes.

SAB tipo 3 - A ardência ocorre em alguns dias, havendo dias livres de sintomas. Ao contrário dos tipos 1 e 2, o sítio de ardência costuma ser pouco comum como assoalho de boca, mucosa jugal e orofaringe. Cerca de $10 \%$ dos pacientes de SAB enquadram-se neste subtipo.

Normalmente, a história dos pacientes evidencia sintomatologia de vários anos de duração. A maioria dos pacientes de SAB relata piora com estresse ou tensão, fadiga, fala (GRUSHKA, 1987) e consumo de alimentos cítricos e condimentados (LAMEY, 1996; VAN DER WÄLL, 1990). Em um grupo de setenta e dois pacientes SAB estudado por Grushka (1987), o repouso e os exercícios físicos tiveram pouco efeito na modificação do ardor ( $80 \%$ dos casos), enquanto que se observou redução 
com o sono (69\%), durante a alimentação (58\%), com alimentos gelados (52\%), trabalho (52\%), lazer (48\%) e com o consumo de bebidas alcoólicas (27\%).

A sensação de lábios e boca seca, disgeusia persistente, gosto amargo ou metálico são sintomas freqüentemente associados à condição (AMENÁBAR et al., 2008; BERGDHAL; BERGDHAL, 1999; GORSKY; SILVERMAN; CHINN, 1991; GRUSHKA; EPSTEIN; GORSKY, 2002a; TANAKA et al., 2002).

\subsection{Diagnóstico}

Nos estudos de Lauritano, Petruzzi e Baldoni (2003) e Petruzzi et al. (2004) todos os sujeitos da pesquisa considerados com SAB localizaram a sensação de ardência na língua ou outro sítio oral, na ausência de lesões clínicas. Os pacientes foram examinados de acordo com os critérios estabelecidos por Berghdal e Anneroth (1994), que incluíam história médica e dental, fluxo salivar, investigação da presença de fungos, exames laboratoriais (hemoglobina, volume corpuscular médio) e presença de anemia.

Todos os pacientes SAB de León Espinosa, López Jornet e Frutos Ros (2004) foram submetidos a um protocolo de coletas de dados a fim de elaborar o diagnóstico, contendo história médica e hábitos dos sujeitos da pesquisa, características da doença como: sintomas referidos, tempo de evolução, características da dor, condições de início dos sintomas e localização. Também se avaliou a evolução dos sintomas com a finalidade de classificar os pacientes segundo o critério de Lamey (1998), além de se observarem sintomas associados 
como alteração de paladar e secura bucal. O exame intra-oral buscou afastar causas locais de ardência, como eritema, fissuras, ulcerações, candidose, fontes de trauma dentário e protético. Exames complementares de sialometria, glicemia, triglicérides, hemoglobina, hematócrito, VCM, HCM, leucócitos e ácido fólico foram solicitados.

Cavalcanti et al. (2007), acompanharam trinta e um pacientes portadores de SAB no serviço de Estomatologia da FOUSP, utilizaram como critério de inclusão pacientes com queixa de ardência sem sinais clínicos que pudessem justificar os sintomas. Em todos os casos um protocolo clínico de diagnóstico foi estabelecido investigando-se o estado de saúde geral e local, por meio de exame físico, exames hematológicos (hematócrito, hemoglobina e glicemia) e mensuração de fluxo salivar não estimulado.

\subsection{Terapêutica}

Uma grande variedade de terapias para o controle sintomático da SAB tem sido proposta, mas o resultado ainda não é satisfatório (SCALA; CHECCHI; MONTEVECCHI, 2003; ZAKRZEWSKA; FORSSELL; GLENNY, 2005). O tratamento é ainda empírico e segue os esquemas sistêmicos ou tópicos, utilizados nas condições neuropáticas crônicas. Esse fato faz com que os pacientes procurem auxílio de diversos especialistas, e façam uso se diversas medicações, ao longo da história de sua doença, como: antifúngicos tópicos, vitaminas do complexo B (LAMEY, 1998), bochechos com substâncias anestésicas (SARDELLA et al., 1999), 
reposição hormonal e drogas ansiolíticas (GRUSHKA; EPSTEIN; MOTT, 1998; TAMMIALA-SOLONEN; FORSSEL, 1999).

Benzodiazepínicos e antidepressivos tricíclicos estão incluídos entre estas opções, apesar de não existirem muitos estudos controlados analisando a utilização destas drogas na SAB. A utilização de baixas doses de amitriptilina e/ou clonazepan é recomendada por alguns autores (GRUSHKA; EPSTEIN; GORSKY, 2002b). Gorsky et al. (1991) consideraram o clorodiazepoxide (Librium $®)$, como droga efetiva e utilizaram também o diazepan (Valium $\left.{ }^{\circledR}\right)$, com bons resultados. Vários pacientes, no entanto, abandonam o uso dos antidepressivos, devido aos efeitos colaterais que podem ser mais incômodos que a própria sensação de ardor (VAN DER WÄLL, 1990).

Woda et al. (1998) avaliaram a eficácia do clonazepan tópico em 25 pacientes (80\% destes faziam uso de antidepressivos e ansiolíticos, que não foram suspensos durante o estudo). Os pacientes eram instruídos a quebrar o tablete na boca e reter a saliva sem deglutir por três minutos, para em seguida descartar o conteúdo. A dose utilizada foi de 0.5 a $1 \mathrm{mg}$, de duas a três vezes ao dia. Houve remissão completa em $40 \%$ dos pacientes (10 casos), enquanto $24 \%$ não apresentaram melhora do quadro. O acompanhamento dos pacientes foi realizado durante 3 meses, sem retorno dos sintomas.

Em outro estudo, melhora do sintoma foi reportada com clonazepan tópico 1mg, três vezes ao dia, em tratamento com duração de duas semanas. Os resultados demonstraram redução significativa na intensidade do ardor em $66 \%$ dos pacientes (GREMEAU-RICHARD et al., 2004).

Maina et al. (2002) testaram a efetividade de três medicamentos: amisulpiride, 50mg/dia; paroxetina, $20 \mathrm{mg} /$ dia e sertralina, $50 \mathrm{mg} / \mathrm{dia}$, durante oito semanas em três 
grupos de 27, 26 e 23 pacientes respectivamente, todos portadores de SAB. A eficácia ficou em torno de $70 \%$ para os três medicamentos, sem efeitos adversos sérios.

Drogas anti-epilépticas inibem o sistema nervoso central, com diminuição da excitabilidade neural e dor. Como exemplo desse tipo de medicamento pode-se citar o clonazepan e a gabapentina. As características dos anti-epilépticos justificam sua utilização como alternativa terapêutica na SAB, no entanto, a gabapentina não demonstrou efetividade (HECKMAN et al., 2006; WHITE et al., 2004).

Femiano, Gombos, Scully (2004) investigaram a ação terapêutica do ácido alfalipóico (ALA) na dosagem de 600mg/dia, paralelamente a um grupo placebo. O ALA foi selecionado devido às suas propriedades de regeneração neurológica, demonstradas no tratamento de desordens neuropáticas crônicas. No grupo tratado, 81\% apresentaram alguma melhora, enquanto no grupo placebo esse percentual foi de $13 \%$ aproximadamente.

A maior ocorrência da SAB em mulheres suscitou a hipótese de que um declínio no nível de estrógeno ocasionaria mudanças no epitélio oral, resultando ardência, entretanto, tratamentos a base de reposição hormonal não apresentaram resultados satisfatórios (FORABOSCO et al., 1992).

Uma revisão dos tratamentos farmacológicos utilizados nos últimos dez anos destinados a aliviar os sintomas da SAB, concluiu que a capsaicina e o clonazepan, administrados via oral, deveriam ser descartados como intervenção terapêutica nesses pacientes devido à severidade dos efeitos adversos. A gabapentina não mostrou eficácia, enquanto o clonazepan tópico até o presente momento se mostrou como a melhor opção, trazendo benefícios significativos a quase metade dos pacientes tratados (SERRA; LIORCA; DONAT, 2007). 


\subsubsection{Capsaicina}

A possibilidade de a SAB constituir-se em um tipo de neuropatia elegeu a capsaicina como alternativa terapêutica. A capsaicina (trans-8-metil-N-vanilil-6nonenamida) tem sido utilizada no tratamento de dores neuropáticas bucais há não muito tempo, sendo também recente o uso em pacientes SAB (GALARZAMANYARI, 2005; HUANG; ROTHE; GRANT-KELS, 1996; LAURITANO; PETRUZZI; BALDONI, 2003; PETRUZZI et al., 2004).

Originada da pimenta vermelha, do gênero Capsicum, a capsaicina é um alcalóide estável que constitui um complexo de capsaicinóides (componentes químicos que dão às pimentas sua ardência característica). Corresponde a molécula ativa responsável por dessensibilizar os nociceptores $\mathrm{C}$ da mucosa bucal (EPSTEIN; MARCOE, 1994;KALIL-GASPAR, 2003).

Terapeuticamente o composto pode ser utilizado de forma tópica ou sistêmica (LEJEUNE; KOVACS; WESTERTERP-PLANTENGA, 2003; NGOM et al., 2001) com profunda dessensibilização funcional. Sua utilização sistêmica produz redução dos sintomas, mas concomitantemente os pacientes podem apresentar problemas gástricos (PETRUZZI et al., 2004). A capsaicina tópica apresenta valores terapêuticos em odontalgias atípicas, dores orofaciais crônicas (VICKERS et al., 1998), neuralgia pós herpética (WATSON et al., 1993), neuropatia diabética, síndrome de dor pós mastectomia (WATSON; EVANS, 1992), dor neuropática oral, neuralgia trigeminal e distúrbios temporo-mandibulares. O grau de alívio geralmente é modesto, embora alguns pacientes tenham reportado bons resultados. (HERSH; PERTES; OCHS, 1994). 
As indicações terapêuticas da capsaicina tópica incluem dores neuropáticas, particularmente acompanhadas de hiperalgesia. Os autores a consideram também como uma opção em pacientes idosos, pela possibilidade da diminuição dos efeitos secundários sistêmicos provenientes das interações medicamentosas, onde a principal indicação do uso tópico é como coadjuvante de antidepressivos e anticonvulsivantes nos diversos quadros de dor neuropática, desde que, como terapia única, parece ser insuficiente. Apesar de alguns estudos demonstrarem uma maior efetividade da capsaicina frente ao placebo, são poucos os pacientes que referem uma resposta expressiva quando a utilizam como terapia única. Dessa maneira seu uso seria especialmente interessante nos casos em que há efeitos secundários dos referidos medicamentos, a fim de reduzir suas dosagens, como complementação da terapia sistêmica (VIDAL et al., 2004).

Tem sido proposto por Ylmaz et al. (2007) que nesses pacientes com dores crônicas ocorre uma super - regulação dos receptores de calor TRPV1 (transient receptor potential vanilloid type 1 ) expressados pelas fibras sensoriais do tipo $C$ na pele ou na mucosa. Esse receptor foi clonado pela primeira vez em 1997 (CATERINA et al., 1997). A capsaicina é considerada um agonista do TRPV1, capaz de dessensibilizar as fibras aferentes vesicais do tipo C (KALIL-GASPAR, 2003; SILVA et al., 2006).

A aplicação do composto parece primeiramente ativar um conjunto de nociceptores que expressam esse receptor, o que resulta no aumento da permeabilidade da membrana para cátions, com liberação de neuropeptídeos a partir de terminações nervosas, tais como a substância $P(S P)$ e conseqüente ardência. A SP, o principal membro da família das taquicininas e mais importante na pele, é um peptídeo de11 aminoácidos, que recebeu essa denominação por parte de 
seus descobridores, meramente devido à forma como era extraída, em pó (do inglês powder). A presença de SP de origem neural na pele parece fortemente controlada pela disponibilidade do fator de crescimento neural (NGF) sintetizado especialmente por ceratinócitos (KALIL-GASPAR, 2003). O estímulo inicial decorrente da aplicação da capsaicina é seguido por um estado duradouro refratário denominado dessensibilização, com claro potencial terapêutico. Esse processo depende de uma variedade de fatores: concentração, duração da aplicação, bem como presença ou ausência de cálcio extracelular. Acontece, então, uma supressão da atividade sensorial das fibras aferentes primárias do tipo C. Ao ligar-se aos receptores TRPV1 ocorre um influxo de cálcio pelo neurônio sensitivo, gerando potenciais de ação que liberam neuropeptídeos nos terminais nervosos periféricos, como a SP (SZALLASI; BLUMBERG, 1999).

A aplicação repetida da capsaicina leva a dois tipos de dessensibilização: uma farmacológica, onde há um declínio progressivo do estímulo em resposta a capsaicina, e outra "funcional" com redução ou perda de outros estímulos também. Essas terminações nervosas parcial ou totalmente degeneradas podem perder contato com células que secretam NGF, responsáveis pela regulação da expressão do TRPV1, SP, e outras moléculas necessárias para a nocicepção (HELIWELL et al., 1998). Na ausência de NGF, a sensibilidade das fibras sensitivas para agonistas do TRPV1 está diminuída, bem como a expressão de TRPV1 e da SP. Mas pode ocorrer reversão do quadro caso a aplicação da capsaicina seja descontinuada, requerendo assim repetidas aplicações para manutenção da eficácia terapêutica (ANAND, 2003).

Os efeitos agudos percebidos imediatamente após a aplicação da capsaicina, como dor ou ardência, são seguidos por um período longo onde ocorrem alterações 
nas fibras sensoriais, que incluem perda de imunoreatividade para receptores TRPV1 e para neuropeptídeos como a SP. Alguns estudos ainda sugerem que a aplicação local de agonistas de TRPV1 diminui a quantidade de NGF nas fibras sensitivas (SILVA et al., 2006).

A dose apropriada de capsaicina aplicada topicamente para um tratamento efetivo de dores neuropáticas, neuralgia pós-herpética, entre outras é 0, 075\% e produz perda profunda de fibras intraepidermais com 24 horas (KHALILI et al., 2001). Lysy et al. (2003) optaram em seu estudo por uma concentração de 0,006\%, aparentemente muito baixa para produzir dessensibilização funcional.

Um estudo clássico da utilização da capsaicina no tratamento de dores neuropáticas foi o de Epstein e Marcoe (1994) em vinte e quatro pacientes (19 mulheres e 5 homens) classificados como portadores de neuralgia trigeminal ou dor neuropática, de acordo com os critérios da Associação Internacional para o Estudo de Dor. Os sujeitos da pesquisa foram tratados com capsaicina tópica a 0, 025\%, quatro vezes ao dia, durante quatro semanas e acompanhados pelo maior tempo possível. A avaliação se deu pela escala visual de sintomatologia (EVS) e relato verbal dos sintomas. O efeito colateral mais comumente observado foi a ardência provocada pela aplicação do medicamento, que ocorreu em 58,3\% dos pacientes onde a remissão se dava entre duas e quatro semanas. Depois de repetidas aplicações, houve completa remissão dos sintomas em $31,6 \%$ dos casos e outros $31,6 \%$ apresentaram melhora parcial. Dois casos tratavam-se de $\mathrm{SAB}$, um paciente apresentou melhora total (controle de 12 meses) enquanto que no segundo a melhora ficou em torno de 10-50\% (controle de 3 meses).Redução maior que 50\% (resolução completa ou resposta parcial) foi relatada pelos indivíduos com dor neuropática (19 pacientes). 
Com a finalidade de testar a efetividade da capsaicina sistêmica no tratamento da SAB, Lauritano, Petruzzi e Baldoni (2003) selecionaram oitenta e quatro pacientes (19 homens e 63 mulheres) divididos em dois grupos. O primeiro recebeu três cápsulas de capsaicina ao dia durante um mês, enquanto o segundo foi tratado com placebo e seguiu a mesma metodologia. A intensidade do ardor foi mensurada pela EVS, com valores de P menor que 0.05 considerados significantes. Não houve relatos de efeitos adversos importantes, registrando-se melhora significativa no grupo tratado com capsaicina $(p<0,05)$.

Petruzzi et al. (2004) em estudo triplo cego e placebo controlado, envolvendo dois grupos de vinte e cinco pacientes com SAB, utilizaram capsaicina em cápsulas na dosagem de $0,25 \%$ ou placebo, via sistêmica, duas vezes ao dia, por 4 semanas. No grupo tratado com capsaicina, dos quinze pacientes com escore de EVS entre 8 e 10, catorze melhoraram; dos oito pacientes com EVS entre 4 e 7, apenas três não apresentaram qualquer melhora após um mês de tratamento. No grupo de vinte e cinco pacientes que utilizaram placebo, apenas um apresentou melhora. Com relação aos efeitos colaterais, casos de progressiva dor gástrica foram reportados no grupo tratado com capsaicina, num total de oito casos (32\%) após quatro semanas de tratamento.

Estudos duplo-cego com capsaicina tópica são de difícil realização, devido à sensação de ardor produzida localmente, no momento da aplicação (VIDAL et al., 2004).

León Espinosa, López Jornet e Frutos Ros (2004) testaram capsaicina tópica em gel na concentração de 0,025 mg em quinze pacientes com SAB (13 mulheres e 02 homens). O gel era aplicado nas áreas com ardência, duas vezes ao dia no início da manhã quando os sintomas eram mínimos e, no final da tarde, quando os 
sintomas estavam exacerbados, por um período de três semanas. Foi recomendado enxaguar a boca com água fria, caso não tolerassem o ardor inicial. Os pacientes foram avaliados durante sete dias consecutivos na primeira semana, e depois reavaliados após quinze dias, completando três semanas. Do total de quinze pacientes, oito (53\%) desistiram na primeira semana por não tolerar o ardor inicial decorrente da capsaicina, dois $(13,3 \%)$ relataram melhora total passando de uma pontuação de EVS de 6,5 iniciais para 2,5 ao final da terceira semana de tratamento; um $(6,7 \%)$ relatou melhora parcial passando de 6 para 4 e quatro $(26,6 \%)$ pacientes não relataram melhora alguma. Os resultados desse estudo mostraram uma efetividade relativamente baixa da capsaicina (13,3\%), devido principalmente ao ardor secundário produzido pela aplicação do medicamento. O autor julgou necessários estudos mais longos, em amostras maiores de pacientes, com apresentações e concentrações diferentes do composto. Apesar da baixa eficácia observada no estudo, os autores recomendaram a utilização da capsaicina no tratamento inicial destes pacientes, como uma alternativa para evitar interações e complicações decorrentes de tratamentos sistêmicos empregados.

Estudo duplo cego realizado no Departamento de Dermatologia do Hospital "Dos de Mayo" (Peru) publicado por Galarza-Manyari (2005), utilizou capsaicina tópica 0,05 e 0,075\% em sessenta pacientes com neuralgia pós - herpética divididos em dois grupos com aplicações de 6 em 6 horas durante 45 dias. No grupo tratado com capsaicina a 0,075\% houve melhora significativa em dezoito pacientes (60\%), reações adversas ( eritema e aumento da dor) ocorreram em cinco pacientes. $\mathrm{Na}$ dosagem de $0,05 \%$ a melhora foi reportada por dezesseis pacientes $(53,3 \%)$ e os efeitos adversos citados anteriormente ocorreram em sete casos. Não foi observada diferença estatisticamente significante entre as concentrações empregadas, a não 
ser o tempo de início de atividade terapêutica e efeitos colaterais que foram menores para a concentração de 0,075\%.

\subsection{Fatores psicológicos associados}

A literatura científica (AMENÁBAR et al., 2008; CAVALCANTI et al., 2007; FORSSELL et al., 2002; HAKEBERG; HALLBERG; BERGGREN, 2003) mostra que estados de ansiedade e depressão estão associados com a etiopatogenia de SAB.

Enfocando o aspecto psicológico das mulheres com SAB, observou-se que todas as pacientes de seu estudo haviam passado por momentos de grande estresse ou decepção durante suas vidas culminando com o aparecimento de dor oral (HAKEBERG; HALLBERG; BERGGRERN, 2003). Estes autores detectaram que estas mulheres tinham alto grau de ansiedade e se auto descreviam como persistentes e exigentes consigo mesmas.

Em estudo realizado no Departamento de Diagnóstico Oral da Universidade de São Paulo e publicado por Cavalcanti et al. (2007) com trinta e um pacientes (28 mulheres e 3 homens) diagnosticados com SAB, a maioria deles $(80,6 \%)$ utilizava cronicamente anti-hipertensivos, ansiolíticos e antidepressivos. Além desse fato, foram referidas alterações nas atividades cotidianas, em conseqüência da SAB, em $29 \%$ dos pacientes.

A SAB quase sempre afeta a qualidade de vida dos pacientes, sendo que grande parte altera seus hábitos alimentares desde o início dos sintomas. De acordo com Grushka (1987), na análise de setenta e dois pacientes, houve mudanças de 
comportamento ou humor em cerca de $70 \%$ destes indivíduos. Gorsky, Silverman e Chinn (1991) afirmam que raramente os sintomas interferem no sono, enquanto outros autores observaram que dois terços dos pacientes têm dificuldade em dormir, ou acordam durante a noite, em conseqüência do ardor (VAN DER PLÖEG et al., 1987). Trata-se de uma condição complexa, que não segue os parâmetros científicos aplicados à maioria das doenças (LAMEY, 1996).

A avaliação psicológica e a psicoterapia são recomendadas como parte do tratamento, devido à alta prevalência dos estados de ansiedade e depressão entre estes pacientes; além da interferência destas condições sobre os sintomas (LAMB; LAMEY, 1988; LAMEY, 1996; TROMBELLI; ZANGARI; CALURA, 1994; VAN DER PLÖEG et al., 1987).

As escalas analógicas visuais têm sido empregadas para avaliar diferentes aspectos subjetivos, como humor (BARTON et al., 1993), dor e particularmente ansiedade. O Inventário de Ansiedade Traço-Estado (IDATE) é um dos instrumentos mais utilizados para quantificar componentes subjetivos relacionados à ansiedade. Desenvolvido por Spielberger, Gorsuch e Lushene em (1970), o IDATE apresenta uma escala que avalia a ansiedade enquanto estado (IDATE-E) e outra que acessa a ansiedade enquanto traço (IDATE-T). Enquanto o estado de ansiedade reflete uma reação transitória diretamente relacionada a uma situação de adversidade que se apresenta em dado momento, o traço de ansiedade refere-se a um aspecto mais estável relacionado à propensão do indivíduo lidar com maior ou menor ansiedade ao longo de sua vida.

Fioravanti et al. (2006) investigaram a estrutura fatorial da escala de ansiedadetraço do IDATE a partir de três amostras brasileiras: estudantes de duas universidades do Rio de Janeiro, estudantes do último ano do ensino médio em 
Brasília e militares em processo de avaliação, detectando diferenças significativas entre gêneros. Mulheres apresentaram escores significativamente maiores em relação aos homens.

Com vistas a identificar humor depressivo em estudos populacionais, tem sido amplamente utilizada em diferentes contextos a Escala de Rastreamento Populacional para Depressão do Centro de Estudos Epidemiológicos (CES-D). Trata-se de um instrumento desenvolvido com a finalidade de detectar sintomas de depressão em populações adultas. A escala compreende itens relacionados a humor, comportamento e percepção que foram considerados relevantes em estudos clínicos sobre depressão (SILVEIRA; JORGE, 1998). 


\section{PROPOSIÇÃO}

Este estudo teve por objetivos avaliar a eficácia da aplicação tópica de capsaicina, como alternativa terapêutica, em um grupo de pacientes portadores da Síndrome de Ardência Bucal (SAB), além de investigar, nessa população, indicativos de ansiedade e depressão, por meio da aplicação do inventário de ansiedade-traço IDATE e da escala de rastreamento populacional para depressão do Centro de Estudos Epidemiológicos (CES-D), correlacionando estes últimos aspectos com a resposta à terapêutica aplicada. 


\section{CASUÍSTICA - MATERIAIS E MÉTODOS}

A pesquisa se desenvolveu no Ambulatório de Diagnóstico Bucal da FOUSP, no período de agosto de 2006 a abril de 2008. Os sujeitos de pesquisa foram convidados a participar do estudo após a confirmação do diagnóstico de SAB, respeitando as condições estabelecidas no projeto de pesquisa. Este estudo obteve aprovação pelo Comitê de Ética e Pesquisa da Faculdade de Odontologia da Universidade de São Paulo (ANEXO - A).

\subsection{Pacientes}

Os pacientes foram seqüencialmente incluídos no grupo estudo após a observação das seguintes condições:

- Estabelecimento do diagnóstico de SAB de acordo com os critérios: sensação de ardência ou queimação bucal, incluindo o segmento anterior da boca, ausência de sinais de doença ou relação com fatores traumáticos locais nas regiões afetadas e duração dos sintomas mínima de quatro meses;

- Fluxo salivar não- estimulado acima de 0,1mL/min.;

- Ausência de anemia, verificada por hemograma;

- Afastamento de diabetes não controlada, verificado por exame hematológico;

- História médica negativa para distúrbios gastrintestinais; 
-História negativa de hipersensibilidade à capsaicina (verificada na anamnese, quando se investigou intolerância a pimentas vermelhas);

- História negativa de tratamento atual ou nos últimos três meses para SAB;

- Concordância com os termos do consentimento livre e esclarecido.

Uma vez satisfeitas às condições anteriores, os pacientes foram divididos em dois grupos: um grupo chamado teste (GT) que recebeu tratamento à base de creme de capsaicina e outro grupo chamado controle (GC) que recebeu como tratamento o creme base sem adição de capsaicina.

Os grupos foram constituídos sem aplicação de técnicas de randomização, de forma seqüencial, na razão de alocação de 3:1, ou seja, uma seqüência de três pacientes foi alocada ao GT e o seguinte ao GC, repetindo-se esse ciclo pelo período em que a pesquisa se realizou. Apenas os pacientes foram mantidos cegos quanto à terapêutica que receberam.

\subsection{Material}

Capsaicina em creme orabase a $0,075 \%$

Creme base (pectina cítrica 5\%, carboximetilcelulose 5\% e água destilada (Q.S. P)

Ficha de protocolo clínico (Cavalcanti, 2003 - ANEXO B)

Escala Visual de Sintomatologia (EVS)

Inventário de Ansiedade Traço-Estado (IDATE) - (ANEXO C)

Escala de Rastreamento Populacional para Depressão CES-D (ANEXO D) 


\subsection{Método}

Os sujeitos da pesquisa foram examinados por um único pesquisador segundo a metodologia rotineira aplicada na Clínica de Diagnóstico Bucal da FOUSP, com auxílio de ficha clínica adaptada ao projeto, que incluiu história detalhada do quadro de SAB de cada paciente, com especial atenção ao tempo de duração, nível de desconforto e características da sintomatologia. Além disso, utilizou-se o critério de Lamey (1998) para classificar o tipo de SAB que os pacientes apresentavam.

Atendidos os critérios clínicos para o diagnóstico de SAB, investigaram-se laboratorialmente outras condições que pudessem estar associadas ao desenvolvimento dos sintomas de ardência bucal, quais sejam diabetes, candidose e anemia. Pacientes com níveis séricos de glicose em jejum superior a $100 \mathrm{mg} / \mathrm{dL}$ foram considerados diabéticos. A presença de anemia foi considerada em níveis de hematócrito inferiores a 36\% para mulheres e 39\% para homens; hemoglobina inferior a 12 g/dL para mulheres e 13 g/dL para homens (HOVE; SCHISANO; BRACE, 2000).

A presença de leveduras foi investigada em todos os pacientes por meio de técnica de citologia esfoliativa, realizada com cytobrush nas áreas de mucosa apontadas pelo paciente como sendo os sítios de localização do sintoma de ardência ou queimação. A identificação de pseudo-hifas à coloração de PAS seria considerada positiva para candidose.

O fluxo salivar foi determinado pela coleta de saliva total não-estimulada, realizada entre $9 \mathrm{~h}$ e $11 \mathrm{~h}$ após período de jejum entre uma e duas horas. Para obtenção da amostra de saliva, o paciente foi colocado sentado em cadeira nãoodontológica, em espaço reservado e orientado a não deglutir a saliva, evitar 
movimentos da língua, lábios e bochechas durante a coleta, descartando o conteúdo bucal em tubo graduado, com auxílio de funil apropriado. A coletada foi realizada por período de 10 minutos e a taxa de fluxo expressa em $\mathrm{mL} / \mathrm{min}$. Valores inferiores a $0,1 \mathrm{~mL} / \mathrm{min}$. foram considerados como indicativos de hipossalivação (SREEBNY, 2000).

\subsubsection{Aplicação dos cremes}

O GT foi tratado exclusivamente com creme a base de capsaicina a 0, 075\% pelo período de dois meses, e reavaliado 30 dias após o término dessas aplicações. Durante o primeiro mês de tratamento, os pacientes foram avaliados semanalmente e no segundo mês, a cada quinze dias.

O GC foi tratado com o creme base utilizado como veículo na preparação contendo capsaicina, observando-se os mesmos períodos de avaliação e controle utilizados no GT.

A aplicação tópica do creme de capsaicina a 0, 075\% para o GT e creme base para o GC, foi realizada em quantidade padronizada $(0,1 \mathrm{cc})$, por meio de colhermedida fornecida aos pacientes, duas vezes ao dia: uma vez ao início da manhã (em torno das 09:00h) e outra vez ao final da tarde ( em torno das 17:00h). Os cremes foram utilizados diariamente durante três semanas, sem interrupção. Após esse período, houve uma semana de intervalo, seguindo-se novo período de aplicação por mais quatro semanas. Trinta dias após o final das aplicações uma nova avaliação de controle foi procedida. 


\subsubsection{Avaliação da resposta terapêutica}

Avaliamos a intensidade da sintomatologia pela aplicação de escala EVS, que consistiu de uma reta graduada de 0 a 10, medindo $100 \mathrm{~mm}$. A pontuação zero da escala indicava a ausência de sintomas, e no extremo direito, a pontuação 10, indicava a intensidade máxima de sintomatologia que o paciente pudesse imaginar. Os pacientes foram orientados a situar seu sintoma dentro desta escala, marcando com um " $X$ " a intensidade de seu sintoma no momento da consulta. Essa escala foi primeiramente apresentada ao paciente previamente ao início das aplicações dos cremes fornecidos, considerando-se esse valor como base de comparação.

Em cada visita de avaliação os pacientes foram solicitados a expressar a severidade de sua sintomatologia por meio da EVS, tanto no GT, quanto no GC.

Após o término do período de observação previsto, os sujeitos da pesquisa, tanto do GT quanto do GC continuaram a ser assistidos pela equipe da Clínica de Diagnóstico Bucal da FOUSP, recebendo, eventualmente, novas orientações terapêuticas, de acordo com os resultados obtidos neste estudo clínico.

O comportamento evolutivo do quadro foi avaliado também pelo Efeito Global Percebido - EGP (Global Perceived Effect - GPE) - determinado pelo julgamento pessoal do paciente sobre o tratamento que recebeu ao término do ciclo terapêutico; através de uma escala de 5 pontos, com as seguintes possibilidades de resposta terapêutica: -1 (piora), 0 (inalterado), +1 (melhora discreta), +2 (melhora evidente), 
+3 (remissão total da sintomatologia). Essa avaliação foi proposta ao final do período de aplicação das medicações.

\subsubsection{Teste de ansiedade Traço-Estado IDATE-T e Escala de Rastreamento Populacional para Depressão - CES-D}

O nível de estresse emocional foi investigado por meio do Inventário de Ansiedade Traço-Estado (IDATE-T); questionário utilizado para avaliar ansiedade. Desenvolvido por Spielberger (1970) na Universidade Vanderbilt. Trata-se de uma escala de auto-relato que depende da reflexão consciente do sujeito no processo da avaliação do seu estado de ansiedade assim como de características de sua personalidade. Dessa forma, a escala mede Ansiedade-Traço, que se refere às diferenças individuais relativamente estáveis na tendência a reagir a situações percebidas como ameaçadoras, com elevações de intensidade no estado de ansiedade.

O teste consta de uma escala de traço de ansiedade com 20 itens que requerem que os sujeitos descrevam como geralmente se sentem. $O$ referido questionário é de acesso público, não havendo necessidade de autorização do autor para a sua utilização. Para mensuração do nível de ansiedade utilizando o questionário IDATE, valores abaixo de 33 foram considerados como baixo, 34-49 médio e a partir de 50, nível alto. Essa avaliação se procedeu ao início da investigação. 
A Escala de Rastreamento Populacional para Depressão - CES-D foi escolhida dentre outros instrumentos pela sua fácil aplicabilidade, pelo seu foco em sintomas depressivos e por ter sido amplamente utilizada para identificar sintomas depressivos na população em geral. Escores elevados refletem a intensidade do desconforto que acompanha a depressão, mas não são diagnósticos desta condição. O instrumento é constituído de 20 itens. As respostas a cada uma das questões são dadas segundo a freqüência com que cada sintoma esteve presente na semana precedente à aplicação do instrumento: "raramente ou nunca" corresponde à pontuação zero; "durante pouco ou algum tempo" corresponde à pontuação um; "ocasionalmente ou durante um tempo moderado" corresponde à pontuação dois; e "durante a maior parte do tempo ou todo o tempo" corresponde à pontuação três. A pontuação pode, portanto, variar entre zero e sessenta (pontuação de zero a três em cada um dos vinte itens).

Para o CES-D o ponto de corte ficou em 15, de forma que valores a partir de 16 foram tidos como sugestivos de depressão. Essa avaliação também foi empreendida ao início do projeto antes dos pacientes iniciarem as aplicações dos cremes utilizados. 


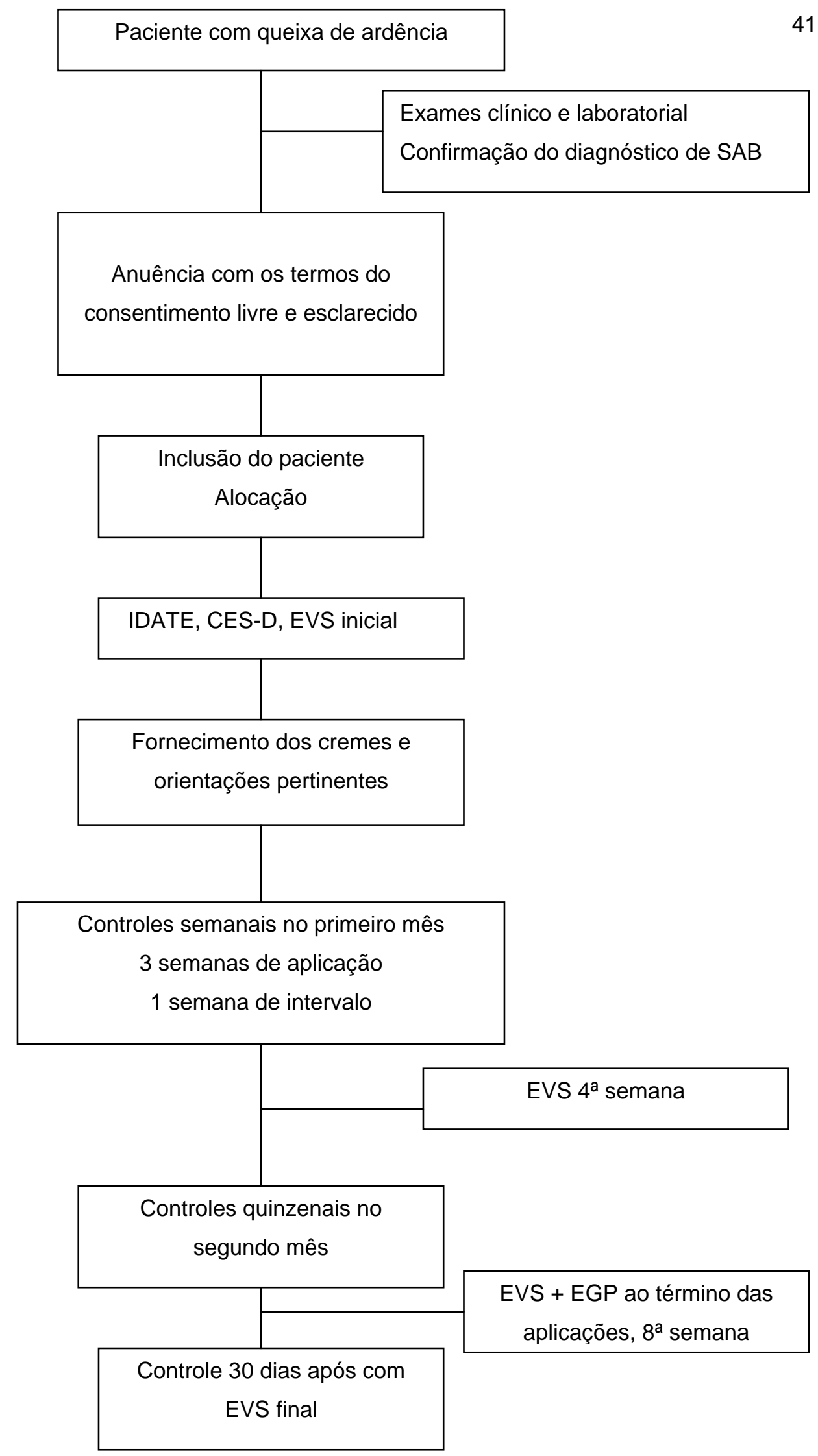

Figura 4.1 - Quadro representativo da seqüência de procedimentos executados no projeto 


\section{RESULTADOS}

\subsection{Pacientes}

Vinte e cinco pacientes foram admitidos ao estudo, uma vez satisfeitas às condições estabelecidas no desenho metodológico. Cinco pacientes foram excluídos da análise dos dados, pois não completaram o tratamento proposto. Dessa forma, vinte pacientes com diagnóstico de $\mathrm{SAB}$, foram efetivamente acompanhados nesta pesquisa clínica (18 mulheres, dois homens, média de idade 60,8 anos). Quinze pacientes foram alocados no GT (14 mulheres e 1 homem), que foi tratado com o creme contendo capsaicina a $0,075 \%$; e cinco pacientes compuseram o GC (4 mulheres e 1 homem), que recebeu como tratamento apenas o creme base utilizado como veículo da preparação com capsaicina.

Em virtude da desistência de alguns pacientes modificamos, ao final do período de composição da casuística, a seqüência pré-estabelecida de alocação dos pacientes na razão de 3:1 entre os grupos de estudo, procurando manter a proporção originalmente planejada.

O perfil demográfico dos pacientes, a divisão destes entre os grupos de estudo, sua história médica e as características de sua sintomatologia encontram-se descritos nas tabelas 5.1 e 5.2 .

A duração média dos sintomas foi de 58,8 meses e as áreas de localização mais freqüentes foram a língua (100\%) e a semimucosa labial (60\%). Em dez casos (50\%) o sintoma afetava múltiplas áreas da mucosa. 
Os tipos de SAB (LAMEY, 1998) distribuíram-se da seguinte forma: três pacientes apresentaram o tipo 3, um paciente o tipo 2 e dezesseis pacientes o tipo 1. O tipo 2 pertenceu ao GC e permaneceu inalterado. Dos pacientes tipo 3 , dois melhoraram e um piorou ao EVS, embora este tenha se declarado inalterado ao EGP. Entre os doze pacientes tipo 1, do GT, oito melhoraram e quatro pioraram. No GC, entre os quatro pacientes do tipo 1, dois permaneceram inalterados, um piorou e um melhorou ao EVS.

Tabela 5.1 - Perfil dos pacientes com SAB $(N=20)$

\begin{tabular}{lll}
\hline Características & GT & GC \\
& $\mathbf{N}(\%)$ & $\mathbf{N}(\%)$ \\
\hline Homens & $01(6,6)$ & $01(20)$ \\
Mulheres & $14(93,3)$ & $04(80)$ \\
Faixa etária (média) & $37-84(61,1)$ & $51-66(60,8)$ \\
Condição sistêmica & & \\
$\quad$ Hipertensão & $07(46,6)$ & $01(20)$ \\
$\quad$ Depressão & $08(53,3)$ & 0 \\
$\quad$ Anemia & 0 & 0 \\
$\quad$ Menopausa & $12(80)$ & $04(80)$ \\
$\quad$ Hipotiroidismo & $01(6,6)$ & 0 \\
$\quad$ Diabetes & 0 & 0 \\
Hábitos & & \\
$\quad$ Tabagismo & $02(13,3)$ & 0 \\
\hline GT - grupo teste & GC - grupo controle &
\end{tabular}


Tabela 5.2 - Características da sintomatologia $(\mathrm{N}=20)$

\begin{tabular}{lcc}
\hline Sintomatologia & GT N (\%) & GC N (\%) \\
\hline Queixas bucais secundárias & $11(73,3)$ & $04(80)$ \\
$\quad$ Xerostomia & $11(73,3)$ & $02(40)$ \\
$\quad$ Alterações do paladar & 58.78 & 58.80 \\
Duração média dos sintomas (meses) & & \\
Padrão sintomatologia & $12(80)$ & $04(80)$ \\
$\quad$ Tipo 1 & 0 & $01(20)$ \\
Tipo 2 & $03(20)$ & 0 \\
Tipo 3 & & $01(20)$ \\
Fatores relacionados ao Início dos sintomas & $06(40)$ & $01(20)$ \\
$\quad$ Locais & $07(46,6)$ & $03(60)$ \\
Emocionais & $03(20)$ & 0 \\
Sem Correlação & $01(6,6)$ & \\
Sistêmico & & $02(40)$ \\
Localização & & $05(100)$ \\
Mucosa jugal, rebordo, palato, orofaringe. & $08(53,3)$ & $04(80)$ \\
Língua & $15(100)$ & \\
Semimucosa labial & $08(53,3)$ & \\
\hline GT - grupo teste $\quad$ GC - grupo controle & & \\
\hline
\end{tabular}

\subsection{Idade e Sexo}

No GT, nove pacientes se colocaram na faixa etária abaixo dos 65 anos de idade (média 53,4 anos), todos pertencentes ao sexo feminino, sendo duas mulheres abaixo dos 50 anos e ainda fora do período do climatério. Entre esses pacientes, sete apresentaram melhora (comparando-se os valores iniciais e controle de 12 semanas) e dois pioraram ao EVS, sendo que estes últimos declararam-se inalterados ao EGP. Além disso, os quatro pacientes que apresentaram remissão total dos sintomas se colocaram dentro desta faixa etária. Ainda no GT, seis pacientes se encontravam na faixa etária acima dos 65 anos (média de 72,5 anos). 
Neste grupo de pacientes idosos, três pioraram, um apresentou melhora discreta e dois, melhora moderada. Nenhum paciente se tornou assintomático.

No GC dois pacientes se encontravam acima dos 65 anos, um piorou e o outro declarou melhora. Os outros três pacientes, abaixo dos 65 anos permaneceram inalterados ao EVS, enquanto um declarou melhora ao EGP.

Os dois únicos homens da casuística se distribuíram um no GT e outro no GC. O sujeito do GC mostrou piora, enquanto o do GT declarou melhora moderada. Ambos se encontravam na faixa etária acima dos 65 anos, não declararam problemas de ordem médica, mas apresentaram níveis de ansiedade elevada e indícios de depressão segundo os testes aplicados nesse sentido.

\subsection{História médica}

Não foram observadas alterações nos níveis de hemoglobina, hematócrito e glicemia em jejum que caracterizassem quadro de anemia ou diabetes na casuística examinada. Apenas dois pacientes exibiram glicemia acima de $100 \mathrm{mg} / \mathrm{dL}$, porém com valores próximos (105 e 115).

Dezesseis dos pacientes utilizavam algum tipo de medicação para tratamento de condição sistêmica crônica, onze com polifarmácia. Oito pacientes apresentaram quadro de hipertensão arterial (40\%), os quais faziam uso contínuo de antihipertensivos. História atual ou pregressa de depressão com acompanhamento profissional e uso de medicamento, foi reportada por oito pacientes (40\%), porém apenas seis pacientes (30\%), encontravam-se atualmente sob medicação com 
antidepressivos, ansiolíticos ou benzodiazepínicos. Não se percebeu qualquer comportamento diferenciado dos pacientes portadores de doenças sistêmicas e os resultados das terapêuticas aplicadas, ou mesmo qualquer correlação estatisticamente significante entre os medicamentos em uso e a resposta terapêutica. O número reduzido de pacientes certamente prejudicou este tipo de análise, considerando-se as ocorrências de uma mesma doença ou de uma mesma classe de medicamentos. Os medicamentos de uso contínuo, identificados na casuística estudada, encontram-se detalhados na Tabela 5.3.

Apenas dois pacientes fumavam, enquanto outros dois haviam suspendido o hábito, um há 03 e outro há 14 anos. Entre os dois fumantes, um apresentou melhora acentuada e outro, piora acentuada.

A pesquisa de leveduras do gênero Candida, levada a efeito por meio de técnica de citologia esfoliativa aplicada às áreas objeto da queixa de ardência resultaram todas negativas para leveduras, recebendo classificação Classe I ou II de Papanicolau, segundo laudos do Laboratório de Patologia Cirúrgica da FOUSP.

Tabela 5.3 - Medicamentos utilizados $(N=20)$

\begin{tabular}{lll}
\hline Medicamentos & GT N(\%) & GC N(\%) \\
\hline Ansiolíticos e antidepressivos & $01(6,6)$ & 0 \\
$\quad$ Benzodiazepínicos & $04(26,6)$ & $01(20)$ \\
$\quad \begin{array}{l}\text { Antidepressivos tricíclicos } \\
\text { Anticonvulsivantes }\end{array}$ & $01(6,6)$ & 0 \\
Anti-hipertensivos & $01(6,6)$ & 0 \\
$\begin{array}{l}\text { Outros medicamentos } \\
\text { Reposição hormonal (estrogênios e } \\
\text { progesterona) }\end{array}$ & $02(13.3)$ & $01(20)$ \\
$\begin{array}{l}\text { Complexo B } \\
\text { Hormônios tireoideanos }\end{array}$ & $01(6,6)$ & 0 \\
Nenhum & $01(6,6)$ & 0 \\
& $01(6,6)$ & 0 \\
& GT - grupo teste & GC - grupo controle
\end{tabular}




\subsection{Fluxo salivar, xerostomia e paladar}

A média de fluxo salivar total não-estimulado da casuística foi de $0,4 \mathrm{ml} / \mathrm{min}$. Apenas dois pacientes apresentaram fluxo salivar abaixo de 0,2 ml/min., um hipertenso e outro sob uso de medicação antidepressiva. Os dois pacientes mostraram melhora com o uso de capsaicina ao EVS (inicial/12 semanas), um com melhora acentuada e outro discreta. Por outro lado, quinze pacientes queixaram-se de algum grau de xerostomia, dez com intensidade discreta, dois moderada, dois severa e um extrema. Entre os três pacientes com xerostomia severa a extrema dois pioraram e um mostrou melhora discreta com o uso da capsaicina, ao EVS. Entre os cinco pacientes sem queixa de xerostomia, quatro do GT e um do GC, quatro melhoraram (3 do GT e 1 do GC) e um piorou (GT). Este paciente que mostrou piora ao EVS, se declarou inalterado ao EGP e apresentou nível de ansiedade elevado, assim como indicativos de depressão.

Onze pacientes do GT e dois do GC declararam alguma alteração do paladar, como gosto amargo ou salgado persistente, ou mesmo perda da acuidade gustativa. Entre os pacientes do GT, quatro pioraram após 12 semanas de controle e sete melhoraram (EVS), sendo que três destes últimos apresentaram remissão total dos sintomas. Ainda no GT, entre os quatro pacientes sem queixa de paladar, três melhoraram (um se tornou assintomático) e um piorou (EVS de 2 para 9 e EGP -1). No GC, os dois pacientes com queixa de alteração de paladar permaneceram inalterados, enquanto dos três pacientes sem queixas nesse sentido, um melhorou, outro permaneceu inalterado e o terceiro declarou piora do quadro após 12 semanas. 


\begin{tabular}{|c|c|c|c|c|c|c|c|c|c|c|c|c|}
\hline $\begin{array}{c}\text { GRUPO } \\
\text { Paciente } \\
\text { n.o }\end{array}$ & Sexo & Idade & $\begin{array}{l}\text { EVS } \\
\text { Inicial }\end{array}$ & $\begin{array}{l}\text { EVS } \\
\text { 28dias }\end{array}$ & \begin{tabular}{|c|} 
EVS \\
56dias
\end{tabular} & $\begin{array}{l}\text { EVS } \\
\text { 84dias }\end{array}$ & $\begin{array}{l}\text { Tipo } \\
\text { SAB }\end{array}$ & $\begin{array}{l}\text { Grau } \\
\text { Xeros- } \\
\text { tomia }\end{array}$ & $\begin{array}{l}\text { Fluxo } \\
\text { salivar }\end{array}$ & IDATE & $\begin{array}{c}\text { CES- } \\
\text { D }\end{array}$ & $\begin{array}{c}\text { EGP } \\
\text { 56dias }\end{array}$ \\
\hline GT1 & $\mathrm{F}$ & 52 & 10 & 7 & 5 & 5 & 3 & 1 & 0,26 & \begin{tabular}{|l|}
38 \\
\end{tabular} & 7 & +2 \\
\hline GT2 & $\mathrm{F}$ & 37 & 3 & 0 & 0 & 0 & 3 & 0 & 0,72 & 40 & 10 & +3 \\
\hline GT3 & $\mathrm{F}$ & 43 & 5 & 5 & 9 & 10 & 1 & 3 & 0,31 & 44 & 14 & 0 \\
\hline GT4 & $\mathrm{F}$ & 65 & 3 & 2 & 1 & 1 & 1 & 0 & 0,39 & 45 & 9 & +2 \\
\hline GT5 & $\mathrm{F}$ & 64 & 6 & 4 & 2 & 3 & 1 & 0 & 0,36 & 46 & 9 & +2 \\
\hline GT6 & $\mathrm{F}$ & 52 & 10 & 7 & 0 & 0 & 1 & 2 & 0,1 & 48 & 18 & +3 \\
\hline GT7 & $\mathrm{F}$ & 80 & 4 & 3 & 3 & 3 & 1 & 3 & 0,1 & 49 & 34 & +1 \\
\hline GT8 & $\mathrm{F}$ & 69 & 2 & 8 & 8 & 9 & 1 & 1 & 0,3 & 50 & 22 & -1 \\
\hline GT9 & $\mathrm{F}$ & 54 & 5 & 0 & 0 & 0 & 1 & 1 & 0,46 & 50 & 21 & +3 \\
\hline GT10 & $\mathrm{F}$ & 84 & 3 & 4 & 4 & 6 & 1 & 1 & 0,2 & 52 & 25 & 0 \\
\hline GT11 & $\mathrm{F}$ & 68 & 3 & 0 & 10 & 10 & 1 & 4 & 0,24 & 53 & 22 & -1 \\
\hline GT12 & $F$ & 64 & 3 & 3 & 3 & 5 & 3 & 0 & 0,28 & 55 & 26 & 0 \\
\hline GT13 & $M$ & 69 & 8 & 6 & 4 & 4 & 1 & 2 & 0,32 & 55 & 20 & +2 \\
\hline GT14 & $\mathrm{F}$ & 54 & 8 & 2 & 1 & 1 & 1 & 1 & 0,48 & 59 & 32 & +2 \\
\hline GT15 & $\mathrm{F}$ & 61 & 3 & 3 & 0 & 0 & 1 & 1 & 0,52 & 67 & 34 & +3 \\
\hline GC1 & $F$ & 66 & 5 & 4 & 4 & 2 & 1 & 0 & 0,5 & 31 & 14 & +3 \\
\hline GC2 & $F$ & 56 & 1 & 1 & - & 1 & 2 & 1 & 0,59 & 35 & 9 & 0 \\
\hline GC3 & $\mathrm{F}$ & 51 & 3 & 3 & - & 3 & 1 & 1 & 0,31 & 43 & 12 & +2 \\
\hline GC4 & $F$ & 60 & 8 & 8 & - & 8 & 1 & 1 & 0,87 & 46 & 23 & 0 \\
\hline GC5 & $M$ & 67 & 5 & 8 & & 10 & 1 & 1 & 0,63 & 58 & 17 & -1 \\
\hline
\end{tabular}

Quadro 5.1 Avaliação dos resultados por EVS e EGP, características demográficas da casuística, tipo de $S A B$, severidade de xerostomia e valores obtidos de fluxo salivar, escore IDATE e escore CES-D, nos grupos teste e controle.

GT - grupo teste; GC - grupo controle; EVS - escala visual de sintomatologia; EGP efeito global percebido; IDATE - Teste de ansiedade Traço-Estado; CES-D - Escala de Rastreamento Populacional para Depressão

\subsection{Escala EVS}

Se considerarmos na escala EVS (1 a 10$)$ os intervalos 1 a 3 como sintomatologia leve; 4 a 6 como moderada e acima de 7 como severa, nossa casuística de quinze pacientes do GT distribuiu-se em sete casos leves, quatro casos moderados e quatro severos. Todos os casos severos apresentaram benefício significativo, ou seja, ao menos $50 \%$ de melhora ao EVS, que manteve correspondência ao EGP, observando-se remissão total em um dos pacientes após 12 semanas. 
Entre os quatro casos com sintomatologia moderada ao EVS, um declarou piora após 12 semanas, um apresentou melhora discreta e dois mostraram melhora acentuada, com um deles declarando-se assintomático após doze semanas. Também se manteve correspondência com os valores de EGP, sendo que o paciente piorado no EVS declarou-se inalterado ao EGP.

Entre os sete pacientes com quadros leves de sintomatologia, quatro pioraram e três melhoraram ao EVS. Dois dos três pacientes beneficiados declararam-se assintomáticos às 12 semanas de controle. Os quatro pacientes que registraram piora ao EVS o fizeram de forma significativa, com dois pacientes declarando valores entre 9 e 10, o máximo de desconforto.

NO GC os cinco pacientes distribuíram-se nesta segmentação do EVS inicial em: um severo, dois moderados e dois leves. Os dois pacientes com EVS na faixa leve permaneceram inalterados, com um deles declarando melhora ao EGP. Entre os dois pacientes com EVS moderado, um piorou e outro melhorou com correspondência ao EGP. O paciente com EVS severo permaneceu inalterado.

Tabela 5.4 - Evolução dos sintomas ao EVS nos controles

\begin{tabular}{lcc}
\hline EVS & GT \% & GC \% \\
\hline EVS média inicial & 5,1 & 4,4 \\
& & \\
EVS média 4 & \\
& 3,6 & 4,8 \\
EVS média 8a. semana & 3,3 & \\
EVS média follow-up & 3,8 & 5,75 \\
\hline
\end{tabular}

GT - grupo teste; GC - grupo controle; EVS - Escala Visual de Sintomatologia 


\subsection{Evolução dos sintomas ao longo dos controles sucessivos}

A intensidade média do sintoma de ardência antes do início dos ciclos de tratamento, mensurado pela EVS, foi de 5,1 (GT) e 4,4 (GC).

No controle de quatro semanas, o conjunto de quinze pacientes do GT, que foi tratado com capsaicina, obteve nível de redução do sintoma avaliado pela EVS em 28,9\% (EVS=3,6), enquanto o GC declarou aumento da sintomatologia em 8,3\% $(E V S=4,8)$. Neste primeiro ciclo de tratamento (3 semanas de medicação e uma de intervalo), no GT, dez pacientes melhoraram, três permaneceram inalterados e dois

pioraram. No GC um paciente reportou melhora, três não demonstraram alteração dos sintomas e um piorou.

Apenas o grupo tratado com capsaicina completou o segundo ciclo. O nível de redução do sintoma do início ao final da oitava semana foi de 34,2\% (EVS- $8^{a}$ semana $=3,3$, enquanto que da quarta para a oitava semana o nível de redução ficou em 8,3\%. Neste período compreendido entre a quarta e oitava semana, no GT, sete pacientes relataram melhora, seis permaneceram inalterados e dois pioraram. No GC a única paciente que retornou para controle permaneceu inalterada.

Entre o início e a décima segunda semana de controle houve redução de $24 \%$ $(E V S=3,8)$, porém, comparando-se a oitava e décima segunda semana observou-se aumento de $13,5 \%$ da sintomatologia no GT. No GC $22.8 \%$ de piora (EVS $=5,75$ ) ocorreu do início até a décima segunda semana; neste período houve redução do EVS em um paciente, três inalterados e piora em um dos casos. Entre a oitava e a 
décima segunda semana (84 dias) não foi reportada melhora por nenhum paciente do GT, sendo que dez mantiveram-se inalterados e cinco pioraram.

Os pacientes do GC não se interessaram em continuar a terapia proposta. A paciente que declarou melhora julgou-se satisfeita com o resultado, cumpriu os controles quinzenais do segundo mês e concordou em retornar para o controle final de 12 semanas. Dos três pacientes que não obtiveram benefício com a aplicação do creme base sem adição de capsaicina, apesar de não cumprirem os controles quinzenais do segundo mês do protocolo estabelecido, consentiram em retornar pra o controle final de 12 semanas. O paciente que piorou após a aplicação do placebo, utilizou capsaicina durante 15 dias, porém os sintomas continuaram intensos e o mesmo preferiu interromper o protocolo e não deu continuidade a nenhuma das terapias propostas em nossa clínica.

Entre os dez pacientes do GT que declararam melhora ao EVS após quatro semanas, seis registraram valores ainda menores ao EVS após 12 semanas do início da terapêutica, um declarou piora acentuada e três se mantiveram estáveis nesse período, sendo que dois destes haviam declarado ausência de sintomas após quatro semanas. Um único paciente que não havia registrado melhora no controle de quatro semanas declarou-se assintomático no controle de 12 semanas.

Três pacientes declararam-se assintomáticos após quatro semanas de controle no GT, destes, no controle de oito semanas, dois mantiveram o resultado, um piorou e dois outros obtiveram remissão total dos sintomas, perfazendo quatro pacientes com EVS zero após 56 dias. Estes últimos quatro pacientes que reportaram completa remissão do ardor com capsaicina mantiveram este resultado até as 12 semanas de acompanhamento. O paciente do GC que manifestou melhora dos sintomas no controle de quatro semanas, relatou que este resultado foi mantido 
após 12 semanas. Aos pacientes que não obtiveram benefício ou se declararam piorados foi oferecida a possibilidade de se engajarem em outras terapêuticas disponíveis no Departamento de Diagnóstico Oral da FOUSP.

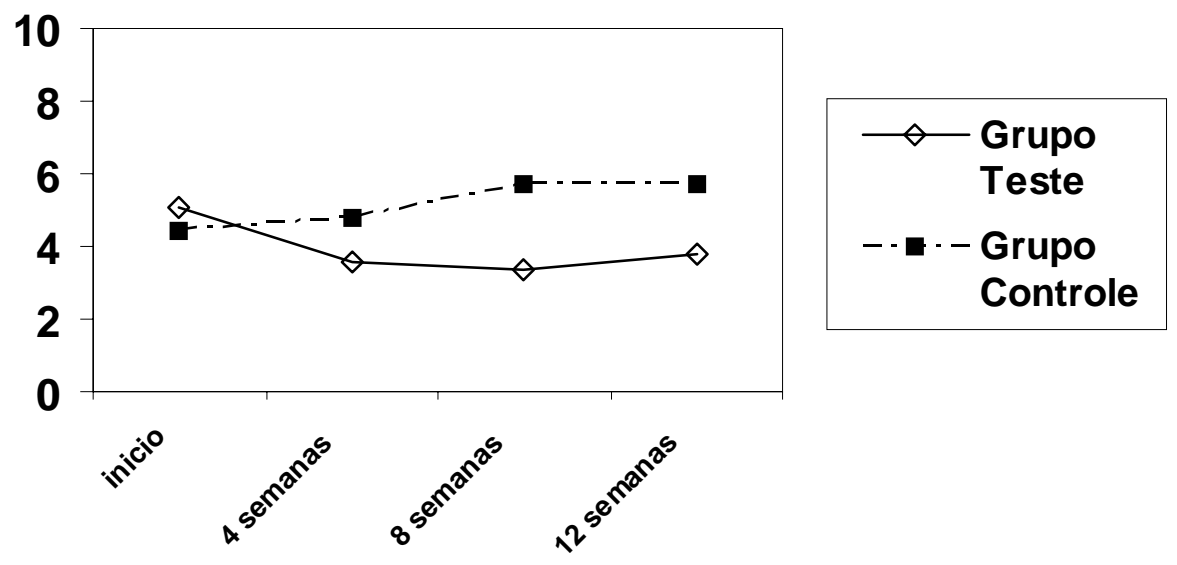

Figura 5.1 Variação da EVS nos controles sucessivos

\subsection{Efeito Global Percebido}

Em termos de EGP, houve pelo menos algum alívio do sintoma $(E G P=+1,+2)$ em seis pacientes (40\%) do GT e em um paciente do GC (20\%). Quatro pacientes $(26,6 \%)$ reportaram remissão total do sintoma $(E G P=+3)$ após tratamento com capsaicina e um paciente (20\%) do controle. Para três pacientes (20\%) do grupo com capsaicina e dois do controle (40\%) não houve modificações do sintoma $(E G P=0)$. Houve relato de piora $(E G P=-1)$ em dois pacientes $(13,3 \%)$ do $G T$ e um (20\%) do GC. 
Todos os pacientes (12) que declararam melhora no EGP também registraram efeito benéfico na EVS. Todos os pacientes (3) que declararam piora do quadro no EGP registraram o máximo de desconforto na EVS. Entre os cinco pacientes que se declararam inalterados no EGP, dois mantiveram esses valores na EVS e três registraram piora significativa na EVS (cerca de $85 \%$ de piora).

Tabela 5.5 - Efeito Global Percebido ao final da terapêutica

\begin{tabular}{|c|c|c|}
\hline EGP (Efeito global percebido) & $\begin{array}{c}\text { GT }(N=15) \\
N(\%)\end{array}$ & $\begin{array}{c}G C(N=05) \\
N(\%)\end{array}$ \\
\hline +1(melhora discreta) & $01(6,6)$ & 0 \\
\hline +2(melhora evidente) & $05(33,3)$ & $01(20)$ \\
\hline +3(resolução total do sintoma) & $04(26,6)$ & $01(20)$ \\
\hline Total n(\%) & $10(66,6)$ & $02(40)$ \\
\hline O(sem modificações no & $03(20)$ & $02(40)$ \\
\hline-1 (piora) & $02(13,3)$ & $01(20)$ \\
\hline
\end{tabular}

GT - grupo teste; GC - grupo controle

\subsection{Questionário IDATE e Escala de Rastreamento Populacional para Depressão (CES-D)}

Sete pacientes do GT apresentaram nível médio de ansiedade. Cinco deles declararam melhora acentuada dos sintomas de ardência, com dois casos de 
remissão completa dos sintomas; um paciente apresentou melhora discreta (EVS de 4 para 3 e EGP +1) e um declarou piora acentuada dos sintomas entre o início do protocolo e o controle de 12 semanas (EVS de 5 para 10 e EGP 0).

Oito pacientes do GT obtiveram escores acima de 50 , considerados como alto nível de ansiedade. Destes, quatro registraram piora ao EVS (2 EGP 0 e 2 EGP -1), e os quatro que melhoraram também o fizeram de forma significativa, com dois pacientes assintomáticos (2 EGP +3 e 2 EGP +2).

No GC um paciente apresentou nível baixo, três mostraram valores médios e um classificou-se como alto. Destes, apenas o paciente com nível baixo de ansiedade mostrou melhora do quadro com o uso do creme placebo (EVS de 5 para 3 e EGP +3). De outro lado, apenas o paciente com elevado nível de ansiedade declarou piora do quadro. Os três pacientes com nível moderado de ansiedade mantiveram-se inalterados ao EVS, embora um deles tenha declarado melhora ao EGP.

Todos os indivíduos com níveis elevados de ansiedade (08) também apresentaram indicativos de depressão (escore acima de 15) e, destes, apenas 50\% melhoraram com o tratamento à base de capsaicina.

No rastreamento para depressão valores acima de 15 foram registrados por dez pacientes $(66,6 \%)$ no GT e no GC dois (40\%) apresentaram suspeita de estado depressivo. Entre os cinco pacientes do GT sem indicativos de depressão, quatro apresentaram melhora da sintomatologia e um declarou piora ao EVS, embora tenha registrado inalterado ao EGP. Quatro dos dez pacientes com maiores indicativos de depressão responderam negativamente ao tratamento com capsaicina. Do restante, três tornaram-se assintomáticos e três melhoraram, comparando-se EVS inicial e a décima segunda semana. No GC, entre os dois pacientes com indicativos de estado 
depressivo, um mostrou piora e o outro permaneceu inalterado. Entre os três pacientes sem indicativos de depressão, um melhorou e dois permaneceram inalterados ao EVS, embora tenham registrado melhora ao EGP.

Tabela 5.6 - Distribuição da casuística segundo grupos estudados e valores obtidos no questionário IDATE.

\begin{tabular}{lcc}
\hline IDATE & $\begin{array}{c}\mathbf{G T}(\mathbf{N = 1 5 )} \\
\mathbf{N}(\%)\end{array}$ & $\begin{array}{c}\mathbf{G C}(\mathbf{N}=05) \\
\mathbf{N}(\%)\end{array}$ \\
\hline Baixo (até 33) & 0 & $01(20)$ \\
Médio (de 34 até 49) & $07(46,6)$ & $03(60)$ \\
Alto (acima de 49) & $08(53,3)$ & $01(20)$ \\
\hline
\end{tabular}

GT - grupo teste; GC - grupo controle; IDATE - Teste de ansiedade Traço-Estado

Tabela 5.7 - Distribuição da casuística e valores obtidos no CES-D.

\begin{tabular}{lcc}
\hline CES-D & $\begin{array}{c}\mathbf{G T}(\mathbf{N}=\mathbf{1 5}) \\
\mathbf{N}(\%)\end{array}$ & $\begin{array}{c}\mathbf{G C}(\mathbf{N}=\mathbf{0 5}) \\
\mathbf{N}(\%)\end{array}$ \\
\hline De 0 até 15 & $05(33,3)$ & $03(60)$ \\
A partir de 16 & $10(66,6)$ & $02(40)$ \\
\hline GT - grupo teste; GC - grupo controle; CES-D - Escala de Rastreamento Populacional
\end{tabular}
para Depressão 


\subsection{Análise estatística}

O tratamento estatístico (teste exato de Fisher) aplicado para a análise dos dados, relacionando os resultados obtidos com o tratamento à base de capsaicina e as variáveis de idade, xerostomia, valores de escala EVS, nível de ansiedade e depressão, não apontaram diferenças significantes entre os grupos avaliados.

As variáveis relacionadas ao sexo, tipo comportamental da SAB (LAMEY, 1998) e história médica não foram submetidas à análise estatística em função da distribuição irregular dos grupos. 


\section{DISCUSSÃO}

As características dos pacientes SAB controlados nesta pesquisa seguiram padrões semelhantes aos veiculados na literatura (HAKEBERG et al., 1997; GRUSHKA; EPSTEIN; GORSKY, 2002ª; LAMEY, 1996; VAN DER PLÖEG et al, 1987; VAN DER WÄAL, 1990) quais sejam: maioria de pacientes do sexo feminino (18:2), após a menopausa (16:2), com freqüentes queixas de xerostomia (15 em 20), distúrbios do paladar (13 em 20), nível elevado de ansiedade (09 em 20) e depressão (12 em 20).

Embora incomodados pelo sintoma de ardência, a cronicidade da condição e experiências terapêuticas frustradas anteriores, tendem a produzir nos pacientes alguma resistência a novas propostas de tratamento, quando não se lhes pode garantir resultado positivo com relativo grau de confiança. Vários pacientes não se interessaram em participar deste estudo em virtude da falta de garantia de resolução do problema, associado ao ceticismo de que a aplicação de um derivado de pimenta pudesse solucionar o quadro de boca ardente. Os sujeitos admitidos apresentaram, em média, cerca de cinco anos de convívio com a condição, sendo que dezessete, entre os vinte pacientes, já haviam procurado ajuda profissional para solução do problema e haviam utilizado algum tipo de tratamento. Doze desses pacientes já haviam experimentado ao menos duas terapêuticas distintas, sem obter resultado satisfatório. Outras investigações observaram condições semelhantes (GRUSHKA; EPSTEIN; MOTT, 1998; LAMEY, 1998; SARDELLA et al., 1999; SCALA; CHECCHI; MONTEVECCHI, 2003; TAMMIALA-SOLONEN; FORSSEL, 1999; ZAKRZEWSKA; FORSSELL; GLENNY, 2005). 
A prevalência da SAB na população mundial é bastante incerta e, na brasileira, completamente desconhecida. Há estimativas de que afete $0,4 \%$ da população americana (MUZIKA; DE ROSSI, 1999). Bergdhal e Bergdhal (1999) apontaram prevalência de 3,7\% em população sueca. A Clínica de Diagnóstico Bucal da FOUSP, que constitui um serviço de referência em Estomatologia na cidade de São Paulo, atende cerca de 3000 pacientes/ano, tendo sido registrados cerca de trinta casos SAB no último ano, representando prevalência de 1\%. Entretanto, não se pode transferir esse dado à população geral, desde que as características da clientela de um ambulatório de Faculdade de Odontologia dedicado ao diagnóstico e tratamento de doenças orais são bastante diversas. Pajukosky et al. (2001), em estudo realizado na Finlândia, observaram prevalência bem maior em idosos e hospitalizados $(12,6 \%$ a $18,3 \%)$. A casuística deste presente trabalho constituiu-se de nove indivíduos até os 60 anos de idade, ou treze até os 65 anos de idade, em um total de vinte pacientes. A média de idade foi de 60,8 anos, observando-se uma curva normal de distribuição por faixa etária, entre a quarta e a nona décadas de vida. Desde que se trata de condição que afeta principalmente as mulheres após a menopausa seria lógico esperar aumento da prevalência com a idade.

A etiologia da SAB ainda se encontra sob investigação. Diversos autores acreditam que fatores locais, sistêmicos e psicogênicos, concorrem para a instalação desta condição (BERGDHAL; BERGDHAL, 1999; CERCHIARI et al., 2006; GRUSHKA, 1987; GRUSHKA; CHING; EPSTEIN, 2006; GRUSHKA; EPSTEIN; GORSKY, 2002a; LAMEY, 1996; VAN DER PLÖEG et al., 1987; VAN DER WÄLL, 1990; SHIP et al., 1995). Nesta última década, as investigações acerca da etiopatogenia da SAB têm se voltado especialmente para o campo das neuropatias periféricas ou centrais, nos mecanismos de condução dos impulsos dolorosos, nas 
disfunções sensoriais envolvendo a gustação e a nocicepção, e processos de degeneração neuropática (BRAILO et al., 2006; ELIAV et al., 2007; FEMIANO, 2004; FORMAKER; MOTT; FRANK, 1998; FORMAKER; FRANK, 2000; FORSSELL et al., 2002; GAO; WANG; WANG, 2000; HAGELBERG et al., 2003; JÄÄSKELÄINEN; FORSSEL; TENOVUO, 1997; LAURIA et al., 2005; PATTON et al., 2007; PURI et al., 2005; TANAKA et al., 2002; YILMAZ et al., 2007).

O esclarecimento da etiologia da doença é geralmente essencial a um tratamento efetivo, e faz parte de nossa educação em saúde jamais tratar um doente sem um correto diagnóstico. Dessa forma, para a paz de nossas consciências, quando não dispomos do conhecimento completo da doença, Ihe conferimos um nome, a classificamos como de etiologia desconhecida e a tratamos sintomaticamente. Assim vem sendo feito com a SAB. A inexistência de uma alteração física da mucosa afetada também dificulta investigações clínicas mais invasivas (BERGDHAL; BERGDHAL, 1999; GRUSHKA; CHING; EPSTEIN, 2006; GRUSHKA; EPSTEIN; GORSKY, 2002b; SANTORO; CAPUTO; PELUSO, 2005). A hipótese de a SAB se tratar de uma neuropatia vem sendo perseguida por diversos autores (GRUSHKA; SESSLE; HOWLEY, 1987; ITO et al., 2002; JÄÄSKELÄINEN; FORSSEL; TENOVUO, 1997), entretanto, apesar dos indícios suportarem essa hipótese, não existem protocolos terapêuticos efetivos já consagrados para o controle desse tipo de doença.

É interessante a ardência situar-se quase exclusivamente no segmento anterior da boca. $O$ fato da língua se apresentar quase sempre afetada transferiu interesse de pesquisa para o sistema gustativo e a inervação associada às papilas gustativas e aos mecanismos relacionados à condução dessa sensação (GRUSHKA; SESSLE; HOWLEY, 1987; ITO et al., 2002; LAURIA et al., 2005). As manifestações clínicas 
dos pacientes acompanhados nesta pesquisa também seguiram o padrão da maior parte dos trabalhos publicados sobre o assunto (AMENÁBAR et al., 2008; BERGHDAL; ANNEROTH, 1994; BERGDHAL; BERGDHAL, 1999; GORSKY; SILVERMAN; CHINN, 1991; LAMEY, 1996; VAN DER WÄAL, 1990). Gaitonde et al. (2002) e Lamey (1996) referiram a possibilidade dos sintomas bucais se apresentarem acompanhados de sintomatologia extra-bucal, entretanto não identificamos pacientes com esta ocorrência em nossa casuística.

Trata-se de uma condição crônica que apresenta a característica de acompanhar o paciente por vários anos. A casuística estudada mostrou duração média em torno de 4,5 anos. Grushka (1987), Lamey (1996) e Van der Waal (1990), referem que a maioria dos pacientes pioram com estresse, fadiga, fala, consumo de alimentos cítricos e condimentados. Neste trabalho registramos catorze (entre vinte) pacientes que declararam agravantes de seu sintoma de ardência, a maioria relacionada a alimentos; havendo referência isolada a dentifrício, tempo seco, cigarros, período pré-menstrual e dois casos de estresse. De outro lado, oito pacientes referiram atenuantes dos sintomas: comer, dormir, consumir água ou frutas geladas. Tal observação também foi constatada por Grushka (1987), que acompanhou setenta e dois pacientes $\mathrm{SAB}$, demonstrando que o perfil dos pacientes e as características da doença são bastante semelhantes, independentemente da localização geográfica das populações estudadas.

As tentativas de caracterização mais detalhada dos quadros clínicos de SAB, com a intenção de se obter subsídios que pudessem se refletir em diagnóstico e tratamentos mais efetivos resultaram em uma classificação publicada por Lamey (1998), porém não há consenso acerca da utilidade real dessa proposta do autor. A casuística desta pesquisa foi classificada segundo esse critério, no entanto, a 
grande maioria se enquadrou no tipo 1, com apenas um paciente do tipo 2 alocado no GC e três pacientes do tipo 3; o que não permitiu qualquer análise em relação à resposta ao tratamento de acordo com o comportamento clínico desses pacientes SAB. Ainda com relação à discussão dos critérios de Lamey (1998), Gorsky, Silverman e Chinn (1991) afirmam que raramente os sintomas interferem no sono, enquanto Van Der Plöeg et al. (1987) observaram dificuldade de dormir em dois terços dos pacientes, em conseqüência do ardor.

O uso de medicação sistêmica de forma contínua constou da história médica de 75\% dos pacientes. Anti-hipertensivos, ansiolíticos e antidepressivos foram os medicamentos mais utilizados. A prescrição de antidepressivos e ansiolíticos, observada em $65 \%$ dos casos, não se dirigia ao tratamento da SAB. Outros autores também observaram o mesmo quadro (BERGDAHL M; BERGDAHL J, 1999; ; GRUSHKA; EPSTEIN; GORSKY, 2002; GRUSHKA; EPSTEIN; MOTT, 1998; HAKEBERG et al., 1997). Embora estes medicamentos sejam empregados no controle do sintoma de ardor, tanto de forma sistêmica (GRUSHKA; EPSTEIN; GORSKY, 2002a; PATTON et al., 2007) quanto tópica (GREEMEAU-RICHARD et al., 2004), o comportamento da casuística neste trabalho não suporta essa indicação terapêutica. As tentativas de tratamento da SAB por meio de ansiolíticos, antidepressivos e drogas anti-epilépticas são diversas, apresentando resultados variáveis, mas raramente beneficiando mais do que a metade dos pacientes tratados. Benzodiazepínicos, amitriptilina, clorodiazepoxide, clonazepan, amisulpiride, sertralina, paroxetina e gabapentina, constituem algumas das drogas ensaiadas na terapêutica da SAB, entretanto, faltam estudos adequadamente controlados para conferir credibilidade aos resultados demonstrados (GORSKY; SILVERMAN; CHINN, 1991; GREMEAU-RICHARD et al., 2004; GRUSHKA; 
EPSTEIN; GORSKY, 2002b; HECKMANN et al., 2006; MAINA et al., 2002; SERRA; LIORCA; DONAT, 2007; WHITE et al., 2004; WODA et al., 1998). Van der Wäll (1990) afirma que muitos tratamentos à base de antidepressivos são suspensos em virtude de efeitos colaterais adversos mais desconfortáveis do que a própria ardência bucal. Femiano, Gombôs e Scully (2004) investigando a ação terapêutica do ácido alfa-lipóico (ALA) obtiveram alguma melhora em 81\% da casuística avaliada, enquanto no grupo placebo esse percentual foi de 13\% aproximadamente, entretanto, trabalho desenvolvido por Cavalcanti, 2008 (aguardando publicação), não obteve resultados terapêuticos positivos.

Ainda em relação ao tratamento medicamentoso da SAB observamos parcela considerável da casuística queixando-se de ardor bucal, apesar da ingestão diária de ansiolíticos e/ou antidepressivos. Tal fato sugere ineficiência deste tipo de medicação no controle desses sintomas, entretanto, não é possível afirmar que a suspensão destes medicamentos não provocaria piora dos sintomas nesses indivíduos, ou mesmo, um número bem maior de pacientes $\mathrm{SAB}$ se toda a população consumidora desses medicamentos, e assintomática, subitamente suspendesse seu uso.

A utilização da capsaicina em pacientes com SAB foi apresentada na literatura como uma alternativa para o controle da doença por Epstein e Marcoe (1994), que se basearam nos benefícios alcançados no tratamento de outras dores crônicas (WATSON; EVANS, 1992; WATSON et al., 1993). A evolução do conhecimento consubstanciando a origem neuropática da SAB vem adicionando bases científicas a uma prática inicialmente bastante empírica (GAO; WANG; WANG, 2000; LAURIA et al., 2005; YILMAZ et al., 2007). Outras aplicações da capsaicina de forma sistêmica ou tópica foram estudadas em dor neuropática oral, neuralgia trigeminal, distúrbios 
temporomandibulares, cefaléia e condições dermatológicas (GRANT-KELS, 1996; HERSH; PERTES; OCHS, 1994; HUANG; ROTHE; VICKERS et al., 1998; LAURITANO; PETRUZZI; BALDONI, 2003; LEJEUNE; KOVACS; WESTERTERPPLANTENGA, 2003; NGOM et al., 2001; PETRUZZI et al., 2004; VIDAL et al., 2004).

Terapeuticamente a capsaicina pode ser utilizada de forma tópica ou sistêmica (GALARZA-MANYARI, 2005; LAURITANO; PETRUZZI; BALDONI, 2003; LEÓN ESPINOSA; LÓPEZ JORNET; FRUTOS ROS, 2004; PETRUZZI et al., 2004). Optamos pela forma tópica, em virtude dos efeitos colaterais (dor gástrica) relatados com a utilização do composto pela via sistêmica (PETRUZZI et al., 2004).

A concentração utilizada foi de $0,075 \%$ de creme de capsaicina para aplicação tópica no GT, realizada em quantidade padronizada $(0,1 \mathrm{cc})$. Achados de Khalili et al. (2001) definiram 0,075\% como a concentração apropriada de capsaicina aplicada topicamente para tratamento efetivo de dores neuropáticas (neuralgia pós-herpética, por exemplo), capaz de produzir perda profunda de fibras intra-epidermais em 24 horas. Annand (2003) também adotou como dose tópica terapêutica 0, 075\%, enquanto Lysy et al. (2003) optaram por uma concentração de 0,006\%, aparentemente muito baixa para produzir dessensibilização funcional. Epstein e Marcoe (1994) foram os primeiros a utilizarem capsaicina tópica para tratamento de SAB na concentração de 0, 025\%. León Espinosa, López Jornet e Frutos Ros (2004) adotaram a mesma dosagem. Galarza-Manyari (2005) utilizaram capsaicina tópica a 0,05 e 0, 075\%, em neuralgia pós - herpética, sem diferença estatisticamente significante entre as concentrações empregadas. Observaram que o tempo de início de atividade terapêutica bem como os efeitos colaterais foram menores para a concentração de 0, 075\%. 
O esquema terapêutico utilizado neste trabalho, que proporcionou aplicações periódicas da capsaicina intercaladas com período de suspensão do medicamento baseou-se tanto nos trabalhos já publicados quanto na expectativa de se perceber as variáveis de eficácia e persistência do efeito terapêutico obtido no curto e médio prazo. Não há consenso, provavelmente em função do reduzido número de investigações já empreendidas, quanto ao regime ideal de aplicação da capsaicina para tratamento da SAB. León Espinosa, López Jornet e Frutos Ros (2004), acompanharam sete pacientes por três semanas; Epstein e Marcoe (1994) aplicaram o medicamento por quatro semanas, enquanto Galarza-Manyari (2005) prescreveram a capsaicina por 45 dias. Nenhum desses autores referiu preocupação com a quantidade de capsaicina utilizada em cada aplicação, variando o número de aplicações diárias e a própria concentração da substância (0, 025\% a 0, 075\%). Todos obtiveram algum grau de melhora da sintomatologia em seus pacientes.

O número e freqüência das aplicações (duas aplicações diárias, uma pela manhã e outra à tarde) basearam-se no padrão de comportamento da SAB tipo 1 (LAMEY, 1998), que representa a maior ocorrência em nossa clínica. Nesse tipo de SAB os pacientes geralmente se queixam de que a ardência se inicia pelo meio da manhã e perdura até o final do dia. Na casuística estudada, 80\% dos indivíduos apresentavam sintomas de ardor diário, com ausência de ardência ao levantar-se, mas que surgia e piorava com o decorrer do dia, principalmente ao anoitecer. Observação semelhante aconteceu nos relatos de Cavalcanti et al. (2007) e León Espinosa, López Jornet e Frutos Ros (2004) onde 48,4\% e 67\% dos pacientes respectivamente foram agrupados dentro deste mesmo subgrupo. Neste último trabalho, as aplicações nas áreas com ardência, se davam duas vezes ao dia no 
início da manhã quando os sintomas eram mínimos e no final da tarde, quando os sintomas estavam exacerbaram-se.

Com relação ao ardor inicial provocado pela aplicação da medicação, este foi relatado durante os primeiros 15 dias de tratamento, regredindo progressivamente com a evolução das aplicações.

Observamos efeito terapêutico da capsaicina em dez pacientes do GT (66,6\%), nas primeiras quatro semanas de tratamento, redução do EVS médio em torno de 28,9\%. No segundo ciclo (8 semanas de tratamento) o nível de redução da sintomatologia no EVS acentuou-se, obtendo-se benefício da ordem de $34,2 \%$. O número de pacientes com melhora manteve-se em dez indivíduos, embora com algumas substituições entre os pacientes. Melhora gradual foi observada por León Espinosa, López Jornet e Frutos Ros (2004) entre a primeira e terceira semanas de tratamento. No trabalho de Epstein e Marcoe (1994), que utilizou quatro aplicações diárias por quatro semanas, houve completa remissão dos sintomas em 31,6\% dos casos e melhora parcial em outros $31,6 \%$.

Ylmaz et al. (2007) sugerem que nesses pacientes com dores crônicas ocorre uma super-regulação dos receptores de calor TRPV1 clonados pela primeira vez em 1997 (CATERINA et al., 1997). A capsaicina é considerada um agonista desses receptores (KALIL-GASPAR, 2003; ANAND, 2003; SILVA et al., 2006). O efeito terapêutico aconteceria pela supressão da atividade sensorial das fibras tipo C, processo iniciado pela ligação aos receptores TRPV1, seguindo-se a liberação de SP e possível exaustão desta, com perda de imunoreatividade para TRPV1 e SP, o que resultaria na redução da sintomatologia de SAB (SILVA et al., 2006). O presente trabalho não é capaz de demonstrar a correção desta teoria, entretanto, os resultados obtidos não a contradizem, uma vez que houve melhoria dos sintomas 
(médios) durante o tempo em que se manteve a aplicação da capsaicina, observando-se ligeira piora da sintomatologia trinta dias após a suspensão das aplicações.

O efeito da capsaicina depende de vários fatores, como: concentração, duração da aplicação, presença ou ausência de cálcio extracelular (SZALLASI; BLUMBERG, 1999). A aplicação repetida pode promover dois tipos de dessensibilização: uma farmacológica, onde há um declínio progressivo do estímulo em resposta à capsaicina, e outra "funcional" com redução ou perda de outros estímulos sensoriais. As terminações nervosas parcial ou totalmente degeneradas podem perder contato com células que secretam NGF, responsáveis pela regulação da expressão do TRPV1, SP, e outras moléculas necessárias para a nocicepção (ANAND, 2003; HELIWELL et al., 1998; SILVA et al., 2006). Nesta pesquisa observou-se a ação "farmacológica" da capsaicina, e não se registrou perdas de outros estímulos sensoriais. Foi comum o relato no sentido de que as aplicações iniciais da substância eram bem mais "ardidas" do que as realizadas nas semanas subseqüentes. Conforme comentado anteriormente, as doses ideais, ou mesmo a freqüência ideal de administração da medicação ainda não se encontram perfeitamente estabelecidas, no entanto, a concentração parece ter sido adequadamente ensaiada e novas investigações deverão esclarecer os pontos ainda obscuros dessa forma de terapia.

A evidente desproporção entre homens e mulheres na casuística estudada, bem como a concentração de quadros sintomatológicos SAB tipo 1 (LAMEY, 1998) não permitiu análises estatísticas desses aspectos. Essa incidência concentrada da SAB em mulheres após a menopausa sugere alguma influência hormonal que, até o momento, não foi demonstrada (FORABOSCO et al., 1992). 
A idade dos pacientes sugeriu alguma influência neste trabalho, ao menos em relação à resposta terapêutica. Entre os pacientes acima dos 65 anos de idade (seis) não houve nenhum caso que tenha se tornado assintomático e apenas $50 \%$ deles apresentou melhora sintomática, enquanto entre os pacientes abaixo dos 65 anos (nove) sete referiram melhora (78\%). É possível que com o avançar da idade a provável neuropatia associada à SAB progrida, ao mesmo tempo em que se reduza a expressão dos receptores sensíveis à capsaicina (TRPV1). Este estudo não teve cunho epidemiológico, de forma que não se pode associar maior prevalência de SAB em faixas etárias mais elevadas. Bergdhal e Bergdhal (1999), na Suécia, em 1427 indivíduos com média de idade de 59 anos; apontou prevalência de SAB de 3,7\%, enquanto Pajukosky et al. (2001), em estudo realizado na Finlândia, com indivíduos mais idosos, observou uma prevalência de 12,6\%, em 75 pacientes hospitalizados (média de idade 82 anos).

A história médica não exerceu influência na resposta terapêutica dos pacientes acompanhados nesta pesquisa. Um fato relevante na casuística foi a ausência de pacientes diabéticos, considerando-se a freqüência dessa doença na população geral. Outro aspecto interessante esteve representado pela negatividade de identificação de fungos do gênero Candida em todas as amostras coletadas para este fim, especialmente pelo fato da língua ter sido o principal sítio dos sintomas de ardência.

A queixa de boca seca definitivamente não correspondeu a um fluxo salivar reduzido na casuística, assim como não houve correlação entre hipossalivação e hipertensão. Nenhum paciente apresentou fluxo salivar não estimulado abaixo de $0,1 \mathrm{~mL} / \mathrm{min}$. e apenas dois pacientes demonstraram fluxo abaixo de $0,2 \mathrm{~mL} / \mathrm{min}$. No entanto, entre os três pacientes com queixa de xerostomia severa, dois pioraram e 
um apresentou melhora discreta com o uso da capsaicina, enquanto entre os cinco pacientes sem queixa de xerostomia, quatro referiram melhora da ardência com o tratamento. Aqui pode haver uma conexão etiológica entre os dois sintomas ardência e xerostomia, desde que a quantidade de saliva disponível freqüentemente não se relaciona à queixa, esse sintoma poderia também estar relacionado a uma deficiência da condução de impulsos sensitivos. Infelizmente não investigamos o comportamento do sintoma de xerostomia antes e após o uso da capsaicina.

Alterações do paladar são freqüentes na $\mathrm{SAB}$, a ponto de se suspeitar de ligação etiológica da inervação responsável pela condução da sensibilidade gustativa com a SAB. Onze dos quinze pacientes do GT queixavam-se de alterações gustativas, destes, sete melhoraram e quatro pioraram dos seus sintomas de ardência com o uso da capsaicina; enquanto entre os quatro pacientes sem queixas gustativas, três melhoraram e um piorou. Mais uma vez, como se trata de um sintoma, assim como a xerostomia e a sensação de ardência, e que compõem a tríade sintomatológica clássica da SAB é possível que haja conexão etiológica e, por conseqüência, interferência na resposta terapêutica. Alteração do paladar referida pelos pacientes desta pesquisa também foi bastante freqüente (13 em 20\%), em concordância com os relatos de diversos autores consultados (AMENÁBAR et al., 2008; BERGDHAL; BERGDHAL, 1999; GRUSHKA; EPSTEIN; GORSKY, 2002a; TANAKA et al., 2002). Não se investigou, neste trabalho, as particularidades dos distúrbios gustativos apresentados pelos pacientes, especialmente devido às características da aplicação de capsaicina que parece agir temporariamente sobre o mecanismo de condução do impulso nociceptivo, sem pretender reparar o defeito neuropático supostamente relacionado à gênese da $\mathrm{SAB}$. 
A investigação dos aspectos subjetivos das doenças é sempre difícil, especialmente quando se lida com pacientes ansiosos, idosos ou com baixo desenvolvimento educacional. Pudemos constatar, por exemplo, que nem sempre houve concordância entre as avaliações de resultados nas escalas EVS e EGP. As escalas analógicas visuais têm sido empregadas para avaliar diferentes aspectos subjetivos, como humor, dor e particularmente ansiedade. Esse tipo de instrumento tem permitido a avaliação desse estado emocional tanto em pacientes ansiosos quanto em pacientes submetidos a situações diversas como: reações de estudantes a exames, situações de dor, procedimentos odontológicos e cirúrgicos e em unidades coronarianas (BARTON et al., 1993).

Classicamente essas escalas são apresentadas ao paciente como uma linha reta de $10 \mathrm{~cm}$, sem qualquer marcação. Neste trabalho as linhas foram divididas em dez segmentos, buscando facilitar a compreensão dos pacientes. A utilização de dois parâmetros de avaliação da sintomatologia (EVS e EGP) também se mostrou útil, ao conferir consistência aos valores obtidos pelo EVS.

Observamos que os pacientes com sintomatologia moderada a severa apresentaram melhor resposta terapêutica do que aqueles com sintomatologia leve, desde que $100 \%$ dos pacientes com sintomatologia severa e $75 \%$ daqueles com moderada referiram melhora após a utilização do creme de capsaicina durante sete semanas. Supõe-se ser mais fácil perceber redução no nível de desconforto em quadros mais severos. Além disso, assumindo-se a ação da capsaicina atrelada aos receptores TRPV1 é bastante provável que tanto o quadro sintomático quanto a resposta ao composto apresentem alguma correlação com a expressão desses receptores em cada indivíduo. 
O comportamento evolutivo dos sintomas no GT demonstra que a capsaicina exerceu efeito benéfico enquanto foi utilizada. Entre a terceira e quarta semanas de controle, período em que foi suspensa a aplicação do medicamento, sete pacientes do GT permaneceram estáveis, quatro melhoraram ligeiramente e quatro pioraram, três de forma leve e um de forma moderada. Entre a oitava semana, última de aplicação da capsaicina, e o controle de doze semanas, cinco pacientes pioraram, dez permaneceram estáveis e nenhum melhorou. Esses resultados parecem demonstrar que a capsaicina mantém efeito residual por pouco tempo, sendo que novos ensaios poderiam estabelecer de forma mais objetiva qual o melhor esquema terapêutico para essa droga - tempo e freqüência de administração. É possível que corrija definitivamente alguma falha na condução do impulso nervoso, ou, ainda, que desempenhe efeito emocional importante, uma vez que manteve estáveis os valores de melhora obtidos durante o período de aplicação do medicamento, ao menos por quatro semanas, em parcela considerável da casuística.

Todos os pacientes avaliados, à exceção de um paciente do GC, apresentaram níveis entre moderados e elevados de ansiedade, sugerindo um traço característico dos pacientes SAB. A literatura científica (AMENÁBAR et al., 2008; CAVALCANTI et al., 2007; FORSSEL et al., 2002; HAKEBERG; HALLBERG; BERGGREN, 2003; LAMB; LAMEY, 1996; LAMEY, 1988; TROMBELLI; ZANGARI; CALURA, 1994; VAN DER PLÖEG et al., 1987) relaciona estados de ansiedade e depressão com a etiopatogenia de SAB.

Além disso, todos os pacientes com elevado nível de ansiedade também demonstraram indicativos de depressão ao escore CES-D e não responderam muito bem ao tratamento proposto. A escala compreende itens relacionados a humor, comportamento e percepção considerados relevantes em estudos clínicos sobre 
depressão (SILVEIRA; JORGE, 1998). Difícil distinguir se os níveis de ansiedade e depressão são decorrentes do desconforto diuturno produzido pela SAB ou se esses distúrbios emocionais foram gerados por outras causas e contribuem de forma direta ou indireta à produção do sintoma de ardência. A instituição de suporte psicoterápico aos pacientes SAB poderia auxiliar no esclarecimento dessas inter-relações. Adicionalmente, seria interessante aplicar testes de avaliação de ansiedade e depressão em variados grupos populacionais, tanto sadios quanto portadores de outras doenças crônicas para melhor comparação desses aspectos. Fioravanti et al. (2006) observaram escores maiores em questionários aplicados para mulheres, que constituem o principal gênero afetado pela SAB.

Não houve uma preocupação estrita em relação ao controle da aderência do paciente ao tratamento prescrito. Uma vez que os exames periódicos dos pacientes foram bastante próximos, esse controle era feito durante a anamnese e pela verificação visual do nível de creme restante nos recipientes fornecidos aos pacientes, muito mais para se verificar a necessidade de suplementação do produto do que para mensurar a quantidade consumida.

Acreditamos que a constituição de um grupo controle bastante menor, quando comparado ao GT e o tamanho reduzido da casuística interferiu na confiabilidade dos resultados e, consequentemente, nos resultados da análise estatística. No delineamento da pesquisa esperávamos contar com um número maior de pacientes, além de um menor número de abandonos, de forma que o protocolo terapêutico deve seguir sendo aplicado, a fim de se alcançar melhor avaliação dos resultados. A diferença de número de sujeitos entre os gêneros também inviabilizou qualquer análise estatística, assim como a distribuição da casuística entre os tipos de SAB propostos por Lamey (1998) apenas um caso tipo 2 e três tipo 3. 
Não foi possível determinar qualquer relação entre os medicamentos ingeridos e o comportamento da $S A B$ ou da resposta obtida com o tratamento à base de capsaicina.

A duração da sintomatologia não pareceu representar fator preponderante à resposta terapêutica à capsaicina, desde que pacientes com até dois anos de queixa e pacientes acima deste tempo de duração apresentaram números semelhantes com relação aos resultados terapêuticos obtidos.

A corrente investigação apresentou aos investigadores envolvidos vários aspectos interessantes e estimulantes à seqüência da pesquisa. Trata-se sem dúvida de uma população complexa, cujo comportamento e perfil parecem exigir a concorrência de equipe multiprofissional para seu adequado manejo. A doença estimula a busca pelas suas bases etiopatogênicas e a resposta terapêutica obtida instigam tentativas de explicação baseadas no pouco conhecimento estabelecido e, muito, no vasto desconhecimento ainda presente em relação às neuropatias idiopáticas. Foi interessante perceber o benefício proporcionado a parte significativa da população controlada, a praticidade das aplicações e o baixo custo da terapia ensaiada. Há vários aspectos a serem desenvolvidos, conforme comentado anteriormente nesta discussão, mas a possibilidade de aplicação imediata do tratamento proposto representa um conhecimento importante e que estimula a continuidade dos estudos. 


\section{CONCLUSÕES}

1. A capsaicina pode ser indicada como alternativa terapêutica a pacientes $S A B$, uma vez que produziu efeito benéfico à maior parte da casuística estudada durante o período de administração do medicamento, prolongando-se até ao menos 30 dias após a suspensão de uso do mesmo, e sem produzir qualquer efeito adverso importante.

2. Indicaríamos o tratamento à base de capsaicina aos pacientes que apresentam intensidade de sintomas entre moderada e severa, desde que esses pacientes responderam de forma mais positiva ao tratamento.

3. Embora os níveis de ansiedade e depressão tenham sugerido alguma influência sobre os resultados do tratamento, estes não se mostraram estatisticamente significantes. 


\section{REFERÊNCIAS ${ }^{1}$}

Amenábar JM, Pawlowski J, Hilgert JB, Hugo FN, Bandeira D, Lhüller F, et al. Anxiety and salivary cortisol levels in patients with burning mouth syndrome: case control study. Oral Surg Oral Med Oral Patho Oral Radiol Endod 2008; 105:460-5.

Anand, P. Capsaicin and menthol in the treatment of itch and pain: recently cloned receptors provide the key. Gut 2003; 52: 1233-5.

Barton CD Jr, Dufer D, Monderer R, Cohen MJ, Fuller HJ, Clark MR, Depaulo JR. Mood Variability in Normal Subjects on Lithium. Biological Psychiatry 1993; 34:87884.

Bergdahl M, Bergdahl J. Burning mouth syndrome: prevalence and associated factors. J Oral Pathol Med 1999; 28(8):350-4.

Berghdal J, Anneroth G. Burning Mouth Syndrome: literature review and modelfor research and management. J Oral Pathol Med 1994; 22:433-8.

Brailo V, Vueiaeeviae-Boras V, Alajbeg IZ, Alajbeg I, Lukenda J, Aeurkoviae M.Oral burning symptons and burning mouth syndrome-significance of different variables in 150 patients. Med Oral Patol Oral Cir Bucal 2006;11:52-5.

Cavalcanti DR, Migliari D. Síndrome de Ardência Bucal: perfil clinico de pacientes e prevalência de leveduras do gênero Cândida. Dissertação Mestrado. São Paulo: Faculdade de Odontologia da USP; 2003.

Caterina MJ, Schumacher MA, Tominaga M. The capsaicin receptor: a heat-activated ion channel in the pain pathway. Nature 1997; 389:816 - 24.

Cavalcanti DR, Birman EG, Migliari DA, Silveira FRX . Burning Mouth Syndrome: Clinical profile of brazilian patients and oral carriage of Candida species. Braz Dent J 2007;18(4):341-5.

Cerchiari DP, Moricz RD, Sanjar FA, Rapoport PB, Moretti G, Guerra MM. Burning mouth syndrome:etiology. Rev Bras Otorrinolaringol 2006;72:419-24.

\footnotetext{
${ }^{1}$ De acordo com Estilo Vancouver. Abreviatura de periódicos segundo base de dados MEDLINE.
} 
Eliav E, Kamran B, Schaham R, Czerninsky R, Gracely RH, Benoliel R. Evidences for chorda tympani dysfunction in burning mouth syndrome patients. J Am Dent Assoc 2007; 138(5):628-33.

Epstein JB, Marcoe JH. Topical application of capsaicin for treatment of oral neuropathic pain and trigeminal neuralgia. Oral Surg Oral Med Oral Pathol 1994; 77:135-40.

Femiano F, Gombos F, Scully C. Burning mouth syndrome (BMS): open trial of psychotherapy alone, medication with alpha-lipoic acid (thioctic acid), and combination therapy. Med Oral 2004; 9:8-13.

Femiano F. Damage to taste system and oral pain: burning mouth syndrome. Minerva Stomatol 2004; 53:471-8.

Fioravanti ACM, Santos LF, Maissonette S, Cruz APM, Landeira Fernandez J.Avaliação da estrutura fatorial da escala de ansiedade-traço do IDATE. Avaliação psicológica 2006; 5:217-24.

Forabosco A, Criscuolo M, Coukos G, Uccelli E, Weinstein R, Spinato S et al.Efficacy of hormonal replacement therapy in post-menopausal women with oral discomfort. Oral Surg Oral Med Oral Pathol Oral Med 1992; 73:570-4.

Formaker Bk, Frank ME. Taste function in patients with oral burning. Chem Senses 2000; 25(5):575-81.

Formaker Bk, Mott AA, Frank ME. The effects of topical anesthesia on oral burning in burning mouth syndrome. Ann N Y Acad Sci 1998; 30:775-80.

Forssell H, Jääskeläinen S, Tenovuo O, Hinkka S. Sensory dysfunction in burning mouth syndrome. Pain 2002; 99:41-7.

Gaitonde P, Rostron J, Longman L, Field EA. Burning mouth syndrome and vulvodynia coexisting in the same patient: a case report. Dent Update 2002; 29(2):75-6.

Galarza-Manyari C. Eficacia y seguridad del tratamiento tópico com capsaicina $0,075 \%$ vs capsaicina $0,050 \%$ em el tratamiento de la neuralgia postherpética.Dermatol Peru 2005;15:108-12. 
Gao S, Wang Y, Wang Z. Assessment of trigeminal somatosensory evoked potentials in burning mouth syndrome. Chin J Dent Res 2000; 3(1):40-6.

Gorsky M, Silverman S, Chinn H. Clinical characteristics and management outcome in the burnin mouth syndrome. Oral Surg Oral Med Oral Pathol 1991; 72:192-5.

Gremeau-Richard C, Woda A, Navez ML, Attal N, Bouhassira D, Gagnieu MC, et al. Topical clonazepam in stomatodynia: a randomised placebo-controlled study. Pain 2004; 108:51-7.

Grushka M. Clinical Features of burning mouth syndrome. Oral Surg Oral Med Oral Pathol 1987; 63:30-6.

Grushka M, Sessle BJ, Howley TP. Psychological assesssment of tactile, pain and thermal sensory functions in burning mouth syndrome. Pain 1987; 28:169-84.

Grushka M, Epstein J, Mott A. An open-label, dose scalation pilot study of the effect of clonazepam in Burning Mouth Syndrome. Oral Surg Oral Med Oral Pathol 1998; 86:557-61.

Grushka M, Epstein JB, Gorsky M. Burning mouth syndrome: diferential diagnosis. Dermatologic Therapy 2002(a); 15, 287-291.

Grushka M, Epstein JB, Gorsky M (b). Burning mouth syndrome. Am Fam Physician 2002(b); 65:615-20.

Grushka M, Ching V, Epstein J.Burning Mouth Syndrome. Adv Otorthinolaryngol 2006; 63:278-287.

Hakeberg M, Bergren U, Häglin C, Ahlqwist M. Reported burning mouth symptoms among middle-aged and elderly women. Eur J Oral Sci 1997; 105:539-43.

Hakeberg M, Hallberg LR-M, Berggrern U. Burning mouth syndrome: experiences from the perspective of female patients. Eur J Oral Sci 2003; 111:305-11.

Hagelberg N, Forssell H, Rinne JO, Scheinin H, Taiminen T, Aalto S, et al. Striatal dopamine D1 end D2 receptors in burnin mouth syndrome. Pain 2003; 101:149-54. 
Heckmann SM, Heckmann JG, Ungethum A, Hujoel P, Hummel T. Gabapetin has little or no effect in the treatment of burning mouth syndrome- results of an open-label pilot study. Eur J Neurol 2006; 13:6-7.

Helliwell RJA, McLatchie LM, Clarke M, Winter J, Bevan S, Mclntyre P. Capsaicin sensitivity is associated with the expression of the vanilloid (capsaicin)

receptor (VR1) mRNA in adult rat sensory ganglia. Neurosci Lett 1998; 250:177-180.

Hersh EV, Pertes RA, Ochs HA. Topical capsaicin - pharmacology and potential role in the treatment of temperomandibular pain. J Clin Dent 1994; 5:54-9.

Hove VL, Schisano T, Brace L. Anemia Diagnosis, Classification and Monitoring using Cell-Dyn technology reviewed for the new millenium. Laboratory Hematology 2000; 6:93-108.

Huang W, Rothe MJ, Grant-Kels JM. The burning mouth syndrome.J Am Acad Dermatol 1996; 34:91-8.

Ito $\mathrm{M}$, Kurita K, Ito T, Arao M. Pain threshold and pain recovery after experimental stimulation in patients with burning mouth syndrome. Psychiatr Clin Neurosci 2002; 56:161- 8.

Jääskeläinen SK, Forssel H, Tenovuo O. Abnormalities of the blink reflex in burning mouth syndrome. Pain 1997; 73:455-60.

Kalil-Gaspar P. Neuropeptides in the skin. An Bras Dermatol 2003; 78:483-98.

Khalili N, Wendelschafer-Crabb G, Kennedy WR, Simine DA. Influence of thermode size for detecting heat paindysfunction in a capsaicin model of epidermal nerve fiber loss. Pain 2001; 91:241-50.

Lamb AB, Lamey PJ, Reeve PE. Burning mouth syndrome: psychological aspects. Br Dent J 1988; 165:256-60.

Lamey PJ. Burning Mouth Syndrome: aproach to successful management. Dental Update 1998; 25(7):298-300.

Lamey PJ. Burning Mouth Syndrome. Dermatologic Clinics 1996;14(2):339-54. 
Lauria G, Majorana A, Borgna M, Lombardi R, Penza P, Padovani A. Trigeminal small-fiber sensory neuropathy causes burning mouth syndrome. Pain 2005;115(3): 332-7.

Lauritano D, Petruzzi M, Baldoni M. Systemic administration of capsaicin for the treatment of the Burning mouth Syndrome.Minerva Stomatol 2003;52:273- 8.

Lejeune MP, Kovacs EM, Westerterp-Plantenga MS. Effect of capsaicin on substrate oxidation and weight maintenance after modest body-weight loss in human subjects. Br J Nutr 2003;90:651- 9.

León Espinosa S, López Jornet P, Frutos Ros R. Síndrome de boca ardiente. Eficácia de la aplicación tópica de capsaicina. Estúdio piloto.Av odontoestomatol 2004; 20:297-304.

Lysy J, Sistiery-Ittah M, Israelit Y, Shmueli A, Strauss-Liviatan N, Mindrul V, Keret D, Goldin E.Topical capsaicin - a novel and effective treatment for idiopathicintractable pruritus ani: a randomised, placebo controlled, crossover study. Gut 2003; 52:1323- 6.

Maina G, Vitalucci A, Gandolfo S, Bogetto F. Comparative efficacy of SSRIs and amilsupiride in burning mouth syndrome: a single-blind study. J Clin Psychiatry 2002; 63:38-43.

Muzika BC, De Rossi SS. A review of burning mouth syndrome. Cutis 1999; 64: 2935.

Ngom PL, Dubray C, Woda A, Dallel R. A human oral capsaicin pain model to asses topical anesthetic- analgesic drugs. Neurosci Lett 2001;316:149- 52.

Pajukoski H, Meurman JH, Halonen P, Sulkava R. Prevalence of dry mouth and burning mouth in hospitalized elderly patients and outpatients in relation to saliva, medication and sistemic diseases. Oral Surg Oral Med Oral Pathol Oral Radiol Endod 2001; 92:641-9.

Patton LL, Siegel MA, Benoliel R, De Laat A. Management of burning mouth syndrome: systematic review and management recomendations. Oral Surg Oral Med Oral pathol Oral Radiol Endod 2007; 103 (suppl): S39.e1-13. 
Petruzzi M, Lauritano D, De Benedittis M, Serpico R.Systemic capsaicin for burning mouth syndrome:short-term results of a pilot study. J Oral Pathol Med 2004; 33: 1114.

Puri V, Cui L, Liverman CS, Roby KF, Klein RM, Welch KM, et al. Ovarian steroids regulate neuropeptides in the trigeminal ganglion. Neuropeptides 2005; 39:409-17.

Santoro V, Caputo G, Peluso F. Clinical and Therapeutic experience in twenty eight patients with burning mouth syndrome. Minerva Stomatol 2005; 54:489-96.

Sardella A, Uglietti D, Demarosi F, Lodi G, Bez C, Carrassi A. Benzydamine hydrocloride oral rinse in management of Burning Mouth Syndrome. Oral Sur Oral Med Oral Pathol 1999; 88:683-6.

Scala A, Checchi L, Montevecchi M. Update on burning mouth syndrome: overview and patient management.Crit Rev Oral Biol Med 2003;14:275-91.

Serra MPM, Liorca CS, Donat FJS. Pharmacological treatment of burning mouth syndrome: a review and update. Med Oral Patol OralCir Bucal 2007;12:299-304.

Ship JA, Grushka M, Lipton JA, Mott AE, Sessle BJ, Dionne RA. Burning Mouth Syndrome: an update. J Am Dent Assoc 1995;126:842-53.

Silva J, Silva C, Diniz P, Cruz . Instilação intra-vesical dos agonistas do TRPV1: aplicação terapêutica. Acta Urológica 2006;23:21-30.

Silveira DX, Jorge MR. Propriedades psicométricas da escala de rastreamento populacional para depressão CES-D em populações clínica e não-clínica de adolescentes e adultos jovens (1998) disponível em URL http://www.hcnet.usp.br/ipq/revista/r255/depre255c. [2008jun21].

Spielberger CD, Gorsuch,R.L, Lushene R.E. Manual for the State-Trait Anxiety Inventory.Consulting Psychologist Press Palo Alto; 1970.

Sreebny LM. Saliva in health and disease: an appraisal and update. Int Den J 2000; 50: $140-61$.

Szallasi A, Blumberg PM. Vanilloid (capsaicin) receptors and mechanisms. Pharmacological Reviews 1999;51:160-202. 
Tammiala- Salonen T, Forssell H. Tradozone in burning mouth pain: a placebocontrolled, double-blind study. J Orofac Pain 1999; 13(2):83-8.

Tanaka M, Kitago H, Ogawa S, Tokunaga E, Ikeda M, Tomita H. Incidence and treatment of dysgeusia in patients with glossodynia. Acta Otolatyngol 2002; Suppl 546:142-5.

Trombelli L, Zangari F, Calura G. The psychological aspects of patients with the burning mouth syndrome. Minerva Stomatol 1994; 43(5):215-21.

Van Der Plöeg HM, Van Der Wäll N, Eijkman MAJ, Van Der Wäll I. Psychological aspects of patiens with burning mouth syndrome. Oral Surg Oral Med Oral Pathol 1987; 63:664-8.

Van Der Wäal I. The Burning Mouth Syndrome. Munksgaard: Copenhagen; 1990.

Vickers ER, Cousins MJ, Walker S, Chisholm K . Analysis of 50 patients with atypical odontalgia. A preliminary report on pharmacological procedures for diagnosis and treatment. Oral Surg Oral Med Oral Pathol Oral Radiol Endod 1998; 85:24-32.

Vidal MA, Calderón E, Román D, Pérez-Bustamante F, Torres LM. Capsaicina tópica em el tratamiento del dolor neuropático. Rev Soc Esp Dolor 2004;11:306-18.

Watson CPN, Tyler KL, Rickers DR, Millikan LE, Smith S, Coleman E. A randomized vehicle-controlled trial of topical capsaicin in the treatment of postherpetic neuralgia. Clin Ther 1993; 15:510-26.

Watson CPN, Evans RJ. The postmastectomy pain syndrome and topical capsaicin: a randomized trial. Pain 1992; 51:375-9.

WhiteTL, Kent PF, Kurtz DB, Emko P.Effectiviness of gabapentin for treatment of burning mouth syndrome. Arch Otolaryngol Head Neck Surg 2004;130:786-8.

Woda a, Naves ML, Picard P,Gremeau C, Pichard-Leandri E. A possible therapeutic solution for stomatodynia (burning mouth syndrome). J Orofac Pain 1998;12:278-8. 
Zakrzewska JM, Forssell H, Glenny AM. Interventionsfor the treatment of burning mouth syndrome. The CochraneDatabase of Systematic Review 2005; Issue 1 Art. No.CD002779.

Yilmaz Z, Renton T, Yiangou Y, Zakrzewska J, Chessel IP, Bountra C, et al. Burning mouth syndrome as a trigeminal small fibre neuropathy: Increased heat and capsaicin receptor TRPV1 in nerve fibres correlates with pain score. J Clin Neurosci 2007; 14(9):864-71. 


\title{
UNIVERSIDADE DE SÃO PAULO \\ FACULDADE DE ODONTOLOGIA
}

\author{
PARECER DE APROVAÇÃO \\ Protocolo 167/06
}

Com base em parecer de relator, O Comitê de Ética em Pesquisa APROVOU o protocolo de pesquisa " ESTUDO CLÍNICO DA ATIVIDADE DA CAPSAICINA EM PORTADORES DA SÍNDROME DE ARDÊNCIA BUCAL", de responsabilidade da Pesquisadora BIANCA FRÉO, sob orientação do Professor Doutor NORBERTO NOBUO SUGAYA.

Tendo em vista a legislação vigente, devem ser encaminhados a este Comitê relatórios anuais referentes ao andamento da pesquisa e ao término cópia do trabalho em "cd". Qualquer emenda do projeto original deve ser apresentada a este CEP para apreciação, de forma clara e sucinta, identificando a parte do protocolo a ser modificada e suas justificativas.

São Paulo, 10 de setembro de 2007

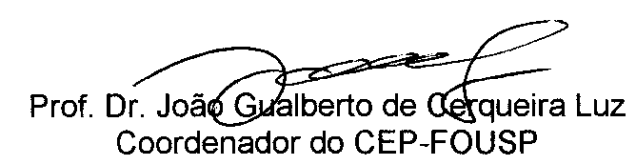

Av. Prof. Lineu Prestes, 2227 - Cidade Universitária "Armando de Salles Oliveira" CEP 05508-900 São Paulo -- SP - Diretoria Telefax: (011) 3091- 0062/3091-7817/3091-7860 - Compras (011) 3091-7895 Impresso no S.D.O. 


\section{Universidade de São Paulo \\ Faculdade de Odontologia \\ Comitê de Ética em Pesquisa}

\section{DE C L A R A Ç Ã O \\ PARECER DE APROVAÇÃO \\ Protocolo 167/06}

Declaramos que o Comitê de Ética em Pesquisa da Faculdade de Odontologia da Universidade de São Paulo recebeu e aceitou o adendo referente à adição de um grupo controle para comparação. Com esse objetivo, será constituído um grupo controle, composto de cinco pacientes portadores de Síndrome de Ardência Bucal, que serão tratados inicialmente com o creme base utilizado como veículo do medicamento, durante um período de trinta dias, do projeto de pesquisa com o título "Estudo clínico da atividade capsaicina em portadores da síndrome de ardência bucal" de responsabilidade da Pesquisadora Bianca Fréo, sob orientação do Professor Doutor Norberto Nobuo Sugaya.

São Paulo, 03 de junho de 2008

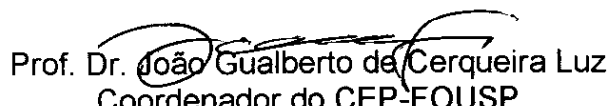

Coordenador do CEP-FOUSP 


\section{PROTOCOLO DE ARDÊNCIA BUCAL (Cavalcanti e Migliari, 2003)}

\section{Identificação:}

Nome:

Endereço:

Tel.:

CEP:

Estado civil: Profissão:

Naturalidade: Nacionalidade:

Grau de instrução:

\section{Caracterização dos sintomas:}

Queixa principal: ( )ardor ( )queimação ( )dor ( )outros

- Tempo de duração: (anos) (meses)

- Localização inicial dos sintomas:

Língua: ( )borda D ( )borda E ( )ápice ( )dorso ( )ventre

Mucosas: ( ) jugal D ( ) jugal E ( )labial inf. ( )labial sup.

Semi-mucosa labial ( )inf. ( ) sup.

( ) palato duro ( )palato mole ( )orofaringe ( )soalho Rebordo alveolar: ( )sup. ( )inf.

- Localização atual dos sintomas:

Padrão de sintomatologia (Lamey, 1996):

( )Tipo I (ardência ausente ao levantar-se, surgindo e piorando com o decorrer do dia)

( )Tipo II (ardência presente ao levantar-se e sem modificações durante o dia ou noite)

( )Tipo III (dias livres de sintomas)

\section{Características gerais do quadro:}

- $\quad$ Fatores associados ao início dos sintomas:

( ) locais

( ) sistêmicos

( ) emocionais

( ) outros 
- Fatores agravantes:

- Fatores atenuantes

- Interferência nas funções bucais e sociais:

- Tratamentos utilizados para resolução do sintoma:
( ) acupuntura
duração:
sessões;
anos
meses

( ) medicação tópica(colutórios, cremes, pomadas):

( ) medicação sistêmica:

( ) outros:

\section{Doenças sistêmicas atuais :}

\section{Pregressas}

História atual ou pregressa de tratamento de depressão

- Uso de medicação sistêmica (especificar droga, concentração, posologia e tempo de utilização):

( )anti-hipertensivos - :

(

( )hipoglicemiantes tempo:

( )ansiolíticos/antidepressivos -

tempo:

( )reposição hormonal tempo:

( )suplementos tempo:

( )outras-

4. Menopausa ( )sim, desde não ( )

5. Hábitos (especificar tipo, quantidade e tempo de uso):

( )tabagismo-

( )etilismo-

( )outros- 


\section{Outras queixas bucais:}

( ) boca seca (prosseguir com avaliação de queixa subjetiva)

( ) alteração de paladar

( )gosto amargo

( ) outras (especificar)

Análise da queixa subjetiva de boca seca (Guy, 1976)

\section{Score ( ):}

0 . Sem queixa de boca seca

1. Sintomas leves de boca seca ao levantar-se ou a noite;

2. Queixa de boca seca várias vezes ao dia, mas sem comprometimento da função (deglutição e fala);

3. Queixas moderadas com certo grau de comprometimento funcional, mas sem percepção de prejuízo à saúde; dificuldade para deglutir alimentos secos ou para falar;

4. Prejuízo severo do bem estar, disfunção severa ou incapacitação, dificuldade em deglutir qualquer tipo de alimento, carrega água e ingere várias vezes ao dia ou dor na boca.

\section{Alimentação:}

Número de refeições/dia: tipo de alimento: ( )arroz ( )feijão ( )frutas

( )verduras: ( )cruas ( )cozidas; ( )carne: ( )vermelha ( )branca

\section{Condição bucal:}

Ausências dentárias: 8765432112345678

8765432112345678

Condição dentária ( )boa ( )regular ( )ruim

Uso de prótese: tipo tempo de uso: frequência:

retenção: estabilidade: integridade:

Indicações terapêuticas: ( )prótese total ( )prótese removível ( )periodontia

( )dentística ( )cirurgia ( )outra

Higiene bucal e da prótese: ( )adequada ( )inadequada

Hábitos parafuncionais(especificar):

Sinais de disfunções temporo mandibulares: ( ) sim ( )não

Exame da mucosa: $\mathrm{N}=$ normal $\quad \mathrm{A}=$ alteração

Língua: ( )borda D ( )borda E ( )ápice ( )dorso ( )ventre

Mucosas: ( ) jugal D ( ) jugal E ( )labial inf. ( )labial sup.

Semi-mucosa labial ( )inf. ( ) sup.

( ) palato duro ( )palato mole ( )orofaringe ( )assoalho

Rebordo alveolar: ( )sup. ( )inf.

Língua ( )geográfica ( )fissurada 


\section{Exames complementares:}

\section{Locais:}

- Pesquisa de fungos (lavado bucal Samaranayake, 1989):

- Contagem (UFC/ml):____ Identificação:

- Saliva: Fluxo Salivar Total Não-Estimulado ( $\mathrm{mL} / \mathrm{min})$ :

Fluxo salivar total estimulado ( $\mathrm{mL} / \mathrm{min})$ :

Proteínas Totais:

$\mathrm{pH}:$

Sistêmicos (Lamey,1996):

- Hemoglobina sérica: Hematócrito:

- Glicemia de jejum: 
ANEXO C - Inventário de Ansiedade Traço-Estado (IDATE)

\section{ANEXO}

Inventário de Ansiedade Traço-Estado - IDATE-T

State-Trait Anxiety inventory (Spilberger et al., 1970) - versāo traduzida e validada por Biaggio e Natalício (1979)

AVALIAÇÃOO

Quase sempre...4 Frequentemente....3 Às vezes...2 Quase nunca...1

Lela cada pergunta e faça um círculo ao redor do número à direita que melhor indicar como você geralmente se sente Não gaste muito tempo em uma única afirmação, mas tente dar a resposta que mais se aproximar de como você se sente geralmente.

\begin{tabular}{|c|c|c|c|c|c|}
\hline Item & Descrição & & & & \\
\hline 1 & Sinto-me bem & 1 & 2 & 3 & 4 \\
\hline 2 & Canso-me facilmente & 1 & 2 & 3 & 4 \\
\hline 3 & Tenho vontade de chorar & 1 & 2 & 3 & 4 \\
\hline 4 & Gostaria de ser tāo feliz quanto os outros parecem ser & 1 & 2 & 3 & 4 \\
\hline 5 & Perco oportunidades porque não consigo tomar decisöes rápidas & 1 & 2 & 3 & 4 \\
\hline 6 & Sinto-me descansado & 1 & 2 & 3 & 4 \\
\hline 7 & Sinto-me calmo. ponderado e senhor de mim mesmo & 1 & 2 & 3 & 4 \\
\hline 8 & $\begin{array}{l}\text { Sinto que as dificuldades estäo se acumulando de tal forma que năo } \\
\text { as consigo resolver }\end{array}$ & 1 & 2 & 3 & 4 \\
\hline 9 & Preocupo-me demais com as coisas sem importância & 1 & 2 & 3 & 4 \\
\hline 10 & Sou feliz & 1 & 2 & 3 & 4 \\
\hline 11 & Deixo-me afetar muito pelas coisas & 1 & 2 & 3 & 4 \\
\hline 12 & Não tenho confiança em mim mesmo & 1 & 2 & 3 & 4 \\
\hline 13 & Sinto-me seguro & 1 & 2 & 3 & 4 \\
\hline 14 & Evito ter que enfrentar crises e problemas & 1 & 2 & 3 & 4 \\
\hline 15 & Sinto-me deprimido & 1 & 2 & 3 & 4 \\
\hline 16 & Estou satisfeito & 1 & 2 & 3 & 4 \\
\hline 17 & $\begin{array}{l}\text { As vezes idéias sem importância entram na cabeça e ficam me } \\
\text { preocupando }\end{array}$ & 1 & 2 & 3 & 4 \\
\hline 18 & $\begin{array}{l}\text { Levo os desapontamentos tăo a sério que não consigo tirá-los da } \\
\text { cabeça }\end{array}$ & 1 & 2 & 3 & 4 \\
\hline 19 & Sou uma pessoa estável & 1 & 2 & 3 & 4 \\
\hline 20 & $\begin{array}{l}\text { Fico tenso e perturbado quando penso em meus problemas do } \\
\text { momento }\end{array}$ & 1 & 2 & 3 & 4 \\
\hline
\end{tabular}


ANEXO D - Escala de Rastreamento Populacional para Depressão CES-D

ANEXO

Escala de Rastreamento Populacional para Depressão

Center for Epidemiologic Studies Depression Scale - CES-D (Radioff, 1977) - tradução e retrotradução por $E$. Doering

Instruções:

Segue abaixo uma lista de tipos de sentimentos e comportamentos.

Solicitamos que você assinale a frequência com que tenha se sentido dessa maneira durante a semana passada

\begin{tabular}{|c|c|c|c|c|}
\hline DURANTE A ÚLTIMA SEMANA : & $\begin{array}{l}\text { Raramente } \\
\text { (menos } \\
\text { que } 1 \text { dia) }\end{array}$ & $\begin{array}{l}\text { Durante } \\
\text { pouco } \\
\text { tempo } \\
\text { (1 ou } 2 \\
\text { dias) }\end{array}$ & $\begin{array}{l}\text { Durante } \\
\text { um tempo } \\
\text { moderado } \\
\text { (de } 3 \text { a } 4 \\
\text { dias) } \\
\end{array}$ & $\begin{array}{l}\text { Durante a } \\
\text { maior parte } \\
\text { do tempo } \\
\text { (de } 5 \text { a } 7 \\
\text { dias) }\end{array}$ \\
\hline $\begin{array}{l}\text { 11. Senti-me incomodado com coisas } \\
\text { que habitualmente nåo me incomodam }\end{array}$ & & & & \\
\hline $\begin{array}{l}\text { 02. Năo tive vontade de comer, tive } \\
\text { pouco apetite }\end{array}$ & & & & \\
\hline $\begin{array}{l}\text { 03. Senti não conseguir melhorar meu } \\
\text { estado de ânimo mesmo com a ajuda d } \\
\text { familiares e amigos }\end{array}$ & & & & \\
\hline $\begin{array}{l}\text { 04. Senti-me, comparando-me às outras } \\
\text { pessoas, tendo tanto valor quanto a } \\
\text { maioria delas }\end{array}$ & & & & \\
\hline $\begin{array}{l}\text { 05. Senti dificuldade em me concentrar } \\
\text { no que estava fazendo }\end{array}$ & & & & \\
\hline 06. Senti-me deprimido & & & & \\
\hline $\begin{array}{l}\text { 07. Senti que tive de fazer esforço para } \\
\text { dar conta das minhas tarefas habituais }\end{array}$ & & & & \\
\hline $\begin{array}{l}\text { 08. Senti-me otimista com relação ao } \\
\text { futuro }\end{array}$ & & & & \\
\hline $\begin{array}{l}\text { 09. Considerei que a minha vida tinha } \\
\text { sido um fracasso }\end{array}$ & & & & \\
\hline 10. Senti-me amedrontado & & & & \\
\hline 11. Meu sono nấ foi repousante & & & & \\
\hline 12. Estive feliz & & & & \\
\hline 13. Falei menos que o habitual & & & & \\
\hline 14. Senti-me sozinho & & & & \\
\hline $\begin{array}{l}\text { 15. As pessoas não foram amistosas } \\
\text { comigo }\end{array}$ & & & & \\
\hline 16. Aproveitei minha vida & & & & \\
\hline 17. Tive crises de choro & & & & \\
\hline 18. Senti-me triste & & & & \\
\hline $\begin{array}{l}\text { 19. Senti que as pessoas não gostavam } \\
\text { de mim }\end{array}$ & & & & \\
\hline $\begin{array}{l}\text { 20. Nẫo consegui levar adiante minhas } \\
\text { coisas }\end{array}$ & & & & \\
\hline
\end{tabular}

